\title{
Protein Kinases in the Pathogenesis of Muscle Wasting
}

\author{
Fabio Penna ${ }^{1}$, Domiziana Costamagna ${ }^{1}$, Andrea Camperi ${ }^{1}$, \\ Maurizio Muscaritoli ${ }^{2}$, Francesco M. Baccino ${ }^{1}$ and Paola Costelli ${ }^{1}$ \\ ${ }^{1}$ Department of Experimental Medicine and Oncology, \\ University of Torino, \\ 'Department of Clinical Medicine, 'Sapienza', \\ University of Roma, \\ Italy
}

\section{Introduction}

The skeletal muscle is a very heterogeneous tissue, that is in charge of a broad range of functions such as movement, stability, heat production and cold tolerance. It represents approximately $50 \%$ of total body protein, and plays a central role in whole body metabolism (Bassel-Duby \& Olson, 2006). In the last two decades, the skeletal muscle, previously considered as a mere protein reservoir, has been shown to release cytokines and other humoral factors (Pedersen \& Febbraio, 2008). This tissue plays a pivotal role in the overall energy balance. Indeed, it regulates lipid flux, takes up and stores most of plasma glucose, and modulates insulin sensitivity. In this regard, the skeletal muscle likely plays a crucial role in pathological states characterized by peripheral insulin resistance such as obesity, as also suggested by recent evidence showing the occurrence of a cross-talk between muscle and the adipose tissue (reviewed in Clarke \& Henry, 2010).

The human body comprises about six hundred different muscles, composed of multinucleated cells organized to form muscle fibers. The myofiber contains many parallel myofibrils, characterized by alternating light (I) and dark (A) bands. The latters are bisected by a dark region ( $\mathrm{H}$ zone), while I bands comprise a dark $\mathrm{Z}$ line ( $\mathrm{Z}$ disk). The interspace between two $Z$ disks is termed sarcomere, the functional unit of the myofibril. Myofibril number defines the cross-sectional area (CSA) of the myofiber, and determines the forcegenerating capacity. Myofibrillar contractile proteins myosin and actin form thick and thin filaments, respectively. Muscle myosin consists of two heavy chains (MyHC), endowed with ATPase activity, and two pairs of light chains (MyLC). Seven different genes coding for embryonic, neonatal and adult MHC isoforms have been described in humans. Myosin is organized in units assembled in a mobile side by side complex, where the head of myosin is at the distal tip of the filament and the tail at the center, rendering the thick filaments bipolar. Myosin heads interact with titin, connecting thick filaments to the $\mathrm{Z}$ disk. In the thin filaments, globular actin monomers are arranged in a double helical conformation, associated with tropomyosin, troponin, and nebulin, that regulate the interactions between actin and myosin. Troponin binds to $\mathrm{Ca}^{2+}$ released from intacellular stores, releasing 
tropomyosin and allowing the interaction between actin and myosin heads. Two actincapping proteins, CapZ and tropomodulin, localized at the positive and negative end of the filament, respectively, prevent actin depolymerization. Finally, the $\mathrm{Z}$ disk is anchored to the sarcolemma by the intermediate filament protein desmin (reviewed in Morel \& PinsetHärström).

Contractile force is generated when myosin associates with actin and then rotates to pull the filaments across each other. Sliding of thick and thin filaments results in sarcomere shortening, due to the ATP-dependent cyclic interactions between the so called crossbridges (protrusions from the myosin molecule, endowed with ATPase activity), and specific binding sites on actin. Contractile force is function of both the isometric lengthtension curve and the speed of contraction, that depends on myosin ATPase activity. Two different types of skeletal muscles can be defined: those characterized by oxidative metabolism and by a long ATPase cycle time, termed slow-twitch, and those that produce energy mainly by glycolysis, with a rapid ATPase cycle, the fast-twich type. Different MyHC isoforms characterize the skeletal muscle types: the type I ( $\beta$, or $\beta$-cardiac) isoform is predominantly expressed in slow fibers, while types IIa, and IIx (also known as IID) are expressed in human fast muscles (reviewed in Oldfor, 2007). Such compartmentalization, however, is not absolute, since several muscles in the body have a mixed composition.

Signals from the motor cortex reach the neuromuscular junction, generating an action potential that is transmitted to muscle fibers, leading to contraction. The performance of the motor unit (motor nerve and muscle fibers) is characterized by mechanical (speed of shortening) and metabolic properties (resistance to fatigue). While the former reflects $\mathrm{MyHC}$ isoform composition (see above), the latter depends on the maintenance of the energy balance. Speed of shortening and resistance to fatigue are strictly correlated. Indeed, slow muscles, characterized by small CSA, few muscle fibers per motor unit, long ATPase cycle time and high oxidative metabolism, display low speed of shortening, but have the possibility to replenish ATP during contraction. As a consequence, they are recruited during tasks that require low force or power but highly precise and long lasting movements. By contrast, fast muscles, that show large CSA, rapid ATPase cycle associated with glycolytic metabolism, are characterized by higher shortening speed then slow ones, but cannot rapidly replace ATP, and are recruited under circumstances when high power output is needed for short time intervals.

The number of muscle fibers in mammals does not change significantly during life, in the absence of injury or disease. Adult skeletal muscle, composed by post-mitotic cells, is endowed with a marked regenerative potential. Indeed, acute muscle injury is rapidly repaired by newly formed myotubes, since myogenic precursors (satellite cells) are conserved also in the postnatal period (Schultz \& McCormick, 1994). In response to regenerative stimuli, satellite cells proliferate to form myoblasts, which divide a limited number of times before terminally differentiating and fusing into multinucleated myotubes (cf. Morgan and Partridge, 2003). Satellite cells are considered an adult stem cell population for the skeletal muscle, that can be renewed without losing the ability to generate differentiated myotubes. However, also other skeletal muscle progenitors have been proposed to contribute to myogenesis. As an example, intramuscular injection of muscleresident side-population cells has been shown to contribute to myofiber formation. Similarly, CD45/Sca1 positive interstitial muscle-resident cells have been shown to acquire 
myogenic activity when cocultured with primary myoblasts or in response to muscle injury or Wnt signaling. The existence of distinct subsets of myogenic cells likely suggests that multiple mechanisms may support regeneration in the adult skeletal muscle, although the contribution of these cells to the maintenance or repair of skeletal muscle under physiologic conditions is uncertain, and their therapeutic potential has not been clearly established.

\section{Physiological regulation of skeletal muscle mass}

In principle, changes of myofiber number and/or dimension, this latter better defined by CSA, result in modulations of the skeletal muscle mass. However, modifications of myofiber number are rarely seen, while variations of CSA may occur frequently. In particular, CSA increases during normal growth or hypertrophy induced, for example, by exercise, and decreases in conditions of inactivity, injury, disease, or aging.

While muscle hypertrophy reflects an accumulation of contractile proteins, the opposite occurs in skeletal muscle atrophy, where both CSA and content of contractile proteins are reduced. On this lines, protein content is the main factor regulating skeletal muscle mass. The amount of proteins in a cell is strictly regulated by the balance between synthesis and degradation rates. In healthy state, protein synthesis and breakdown do not exceed each other, allowing normal protein turnover without modifying the skeletal muscle mass. Although modulations of both sides of turnover eventually converge to produce a new steady-state, physiologic muscle hypertrophy mainly result from increased rates of protein synthesis, which responds earlier than degradation to the inducing stimuli. By contrast, increased breakdown rates are in charge of protein depletion in many situations characterized by muscle atrophy.

A complex interplay among humoral mediators such as insulin and IGFs, and amino acids is involved in regulating the rates of intracellular protein synthesis. In this regard, signaling through the insulin/IGF-1 receptor, as well as increased amino acid levels, have been shown to simultaneously stimulate synthesis and inhibit protein catabolism. Protein synthesis induction by classical anabolic signals such as insulin or IGF-1 relies on the activation of a transduction pathway involving phosphoinositide-3-kinase (PI3K), Akt/PKB, mTOR (mammalian Target Of Rapamycin), and p7056K (p70 ribosomal S6 kinase). As an example, this pathway has been shown to account for the generation of muscle hypertrophy induced by resistance exercise (reviewed in Adamo \& Farrar, 2006). The demonstration that the $\mathrm{PI} 3 \mathrm{~K} / \mathrm{Akt} / \mathrm{mTOR}$ pathway is crucial to skeletal muscle increase in size has come from studies reporting that the expression of a constitutively active form of Akt in skeletal muscle cells, or its conditional activation in the skeletal muscle of adult rats, result in the appearance of a hypertrophic phenotype (Rommel et al., 2001; Lai et al., 2004). Similar patterns can be reproduced by administering a mixture of the 3 branched-chain amino acids (BCAAs: leucine, isoleucine, and valine), or even leucine alone. In addition to provide substrate for the assembly of new proteins, amino acids interfere with different transduction pathways involved in the regulation of mRNA translation (Kadowaki \& Kanazawa, 2003). In particular, increased leucine intracellular concentrations have been shown to enhance the rate of translation by activating p7066 and eIF-4F (eukaryotic Initiation Factor $4 \mathrm{~F}$ ), independently from Akt (Lang and Frost, 2005). The body protein-sparing effect of leucine has been suggested by the observation that nitrogen balance in fasting volunteers treated with leucine alone or with BCAA keto acid analogues is improved (Choudry et al., 2006). 
The regulation of protein synthesis exerted by amino acids mainly relies on mTOR, a serine/threonine kinase crucially involved in cell growth. mTOR stimulates protein synthesis through three key regulatory proteins: p7056K, 4E-BP1 (eukaryotic initiation factor 4E-binding protein 1) and eIF-4G (eukaryotic Initiation Factor 4G). Reduced mTORmediated signaling has been reported in the skeletal muscle of fasted rats compared with the fed state. As expected, also the levels of phosphorylated 4E-BP1 are decreased in fasted animal; this would result in eIF-4E sequestration, inhibiting the assembly of the initiation complex eIF-4F. By contrast, 4E-BP1 is markedly hyperphosphorylated in the skeletal muscle of rats fed a high protein diet, promoting the formation of the eIF-4F complex. Moreover, leucine also promotes phosphorylation of p70s6K (Anthony et al., 2000). Akt activation also induces GSK-3 $\beta$ phosphorylation, thus resulting in its inactivation. GSK-3 $\beta$ negatively regulates molecules involved in several anabolic processes and most of its effects are mediated by the PI3K/Akt pathway, in which GSK-3 $\beta$ acts both as a downstream target and as a negative regulator (Hanada et al., 2004). Consistently, non-competitive inhibition of GSK-3 $\beta$, by means of transfection with a dominant-negative cDNA, or by pharmacological compounds, activates the PI3K/Akt pathway, resulting in myotube hypertrophy (Rommel et al., 2001; Van der Velden et al., 2006). In addition, the increased proteolysis observed in muscles isolated from burned rats can be prevented by addition of GSK-3 $\beta$ inhibitors to the incubation medium (Fang et al., 2005). Other studies have shown that GSK-3 $\beta$ is involved in the pathogenesis of Alzheimer disease, prionic diseases, Hungtington corea, and gp-120 HIV-related neurotoxicity (Jope, 2003). All these considerations suggest that specific GSK-3 $\beta$ inhibitors could be useful from a clinical point of view in order to correct muscle hypotrophy in wasting diseases such as cancer, HIV, cardiac cachexia, diabetes and to interfere with the pathogenic mechanisms of above cited neurologic diseases.

As for protein breakdown, it is also highly relevant to muscle homeostasis. Indeed, this process not only accounts for the degradation of damaged proteins as well as of regulatory molecules such as cyclins and their inhibitors, but also plays a crucial role in maintaining the right cellular size (Waterlow, 1984). The mobilization of muscle protein may have a physiological significance when aimed at providing substrates for both gluconeogenesis and the synthesis of the acute phase reactants. However, up-regulations of protein degradation rates exceeding protein synthesis may result in skeletal muscle wasting (see below). From this point of view, the intuitive means to counteract the loss of muscle mass resulting from protein hypercatabolism, is to increase protein synthesis. However, in terms of rate equations, protein synthesis is a zero-order process, while degradation of the bulk of cell proteins is a first-order process described by a fractional rate constant. Consequently, under a given set of regulations, the size of the protein pool does not affect the fraction of proteins degraded. This means that, if the breakdown rate constant is higher than physiologic levels, protein loss will occur irrespectively of the protein synthesis rate (cf. Costelli and Baccino, 2003).

\section{Mechanisms involved in muscle mass changes}

Muscle protein mass is regulated by both anabolic and catabolic signals. In particular, alterations in the balance between the two result in modulations of the skeletal muscle size, towards accretion or depletion when anabolic or catabolic pathways are prevailing, respectively. In this regard, pathological muscle depletion is characterized by a negative 
nitrogen balance which results from disruption of the equilibrium between anabolism and catabolism, due to reduced synthesis, increased breakdown, or both.

Generally speaking, muscle hypertrophy, either compensatory or due to working overload, is associated with up-regulation of protein synthesis. As reported above, particularly relevant in this regard are the activation of the PI3K/Akt/mTOR pathway induced by engagement of both insulin and IGF-1 receptors, as well as amino acid availability, BCAA in particular (see above). In addition, an important role in skeletal muscle enlargement is played by the protein phosphatase calcineurin (Musarò et al., 1999). As an example, rat myoblasts exposed to IGF-1 show a marked hypertrophic response that involves the enhancement of calcineurin expression, and that can be inhibited by the immunosuppressant agent cyclosporin A (Musarò et al., 1999). Similar observations have been performed also in the whole animal, where muscle hypertrophy induced by functional overload can be prevented by pharmacological inhibition of calcineurin with cyclosporin A or FK506 (Dunn et al., 1999).

While the regulation of protein synthesis is substantially well defined, the mechanisms underlying the activation of cell protein degradation to supraphysiological levels have not been completely elucidated. Intracellular proteolysis in the skeletal muscle is operated by several systems. The lysosomal and the proteasomal ones, are able to degrade proteins into amino acids or small peptides. By contrast, both the $\mathrm{Ca}^{2+}$-dependent and the caspase pathways, characterized by a restricted catabolic specificity, only lead to a limited proteolysis of their substrates.

The ATP-ubiquitin-dependent proteasome system is mainly involved in the degradation of damaged or rapid-turnover proteins. Degradation of its substrates mostly requires the covalent attachment of at least four ubiquitin molecules; the presence of such polyubiquitin chain targets the substrate to the $26 \mathrm{~S}$ proteasome, a large cytosolic proteolytic complex. Both proteasomal activity and substrate ubiquitylation are ATP-dependent processes. About twenty years ago, the ubiquitin-proteasome system has been shown to contribute significantly also to bulk protein degradation. This has become clear when increased expression of molecules pertaining to this proteolytic system have been reported in experimental conditions characterized by muscle wasting, the more so when two musclespecific ubiquitin ligases, namely MAFbx/atrogin-1 and MuRF1 have been identified (reviewed in Costelli and Baccino, 2003). The former, in particular, is a component of the SCF complex, involved in targeting proteins for proteasomal degradation; such complex is formed by two molecules, SKP-1 (S) and Cullin-1 (C), that may be associated with a large series of F-box subunits (F), responsible for substrate specificity (Kipreos and Pagano, 2000). The results reported in the literature show that muscle wasting in several conditions such as sepsis, denervation, AIDS, diabetes, and cancer is associated with increased gene expression of both atrogin-1 and MuRF1 (Lecker et al., 2004). While the mechanisms regulating these ubiquitin ligases are not yet completely elucidated, hyperexpression of atrogin- 1 has been proposed to depend on reduced signaling through the insulin/IGF-1 anabolic pathway (Sandri et al., 2004; Stitt et al., 2004), while activation of the NF-кB transcription factor, likely cytokine-dependent, seems to drive the increase of MuRF1 mRNA levels (Cai et al., 2004).

The autophagic-lysosomal degradative pathway, relatively non selective, is mostly responsible for the degradation of long-lived proteins as well as for the disposal of damaged 
organelles (reviewed in Scott \& Klionsky, 1998). Autophagy relies on the sequestration of portions of cytoplasm into double-membrane vesicles (autophagosomes). These fuse with lysosomes, where the autophagic body is lysed, its content broken down, and the resulting degradation products made available for recycling (see Scott and Klionsky, 1998). Autophagy has been described in mammalian cells since the 1960s, however the underlying molecular mechanisms have been elucidated in the last years, with the identification of a set of genes named ATG (autophagy-related; Klionsky et al., 2003). Autophagy occurs at a basal rate in normal growth conditions, however, it can be markedly enhanced by specific environmental stresses. A crucial role in the regulation of autophagic rate is played by mTOR (see above). Under nutrient-rich conditions mTOR is active and autophagy is inhibited. By contrast, mTor is inactivated by nutrient starvation, and autophagic degradation is enhanced (Codogno \& Mejier, 2005). The contribution of autophagy to skeletal muscle protein breakdown has been recognized only in the last years, although an altered lysosomal function has previously been reported in several myopathies (Bechet et al., 2005). In this regard, the skeletal muscle has been shown to respond to a classical autophagic stimulus such as starvation by increasing the levels of the autophagic marker LC3B-II (Mizushima et al., 2004). These results are consistent and further substantiate previous reports showing that autophagy is the main proteolytic pathway involved in the amino acid-dependent regulation of proteolysis in cultured myotubes (Bechet et al., 2005). On this line, increased gene expression of cathepsins L or B has been reported in the skeletal muscle of septic or tumor-bearing animals (Deval et al., 2001) as well as in muscle biopsies from lung cancer patients (Jagoe et al., 2002). In addition, skeletal muscle wasting in tumor-bearing rats has been shown to be associated with enhanced activity of lysosomal proteases (Greenbaum and Sutherland, 1983; Tessitore et al., 1993). Consistently, administration of leupeptin, an inhibitor of cysteine proteases, counteracts the loss of muscle mass that occurs in sepsis and in experimental cancer cachexia (Ruff and Secrist, 1984; Tessitore et al., 1994). More recently, ATGs have been shown to be induced in muscle by denervation or fasting, through a FoxO3-dependent mechanism (Zhao et al., 2007). In this regard, FoxO3 has been proposed to regulate both autophagy and proteasome-dependent proteolysis (Zhao et al., 2007). However, a sort of hierarchy appears to exist between these two processes, since a parallel study shows that autophagic degradation induced by starvation or FoxO3 overexpression is sufficient to determine muscle depletion even if the ubiquitinproteasome degradation is blocked using pharmacological or genetic approaches (Mammucari et al., 2007).

Quite intriguing is the role of the $\mathrm{Ca}^{2+}$-dependent proteolytic system in the pathogenesis of muscle protein hypercatabolism. Cysteine proteases called calpains, and a physiological inhibitor named calpastatin, are the components of the $\mathrm{Ca}^{2+}$-dependent proteolytic system. Calpains have been involved in processes such as cell proliferation, differentiation, migration, apoptotic death, and gene expression (Suzuki et al., 2004). A number of proteins, among which protein kinase $\mathrm{C}, \mathrm{Cdk} 5, \mathrm{Ca}^{2+} /$ calmodulin-dependent protein kinase IV, calcineurin, titin and nebulin have been proposed as in vivo calpain substrates (reviewed in Suzuki et al., 2004). Due to restricted specificity, however, calpain action is limited, and generally leads to irreversible modifications of the substrates, resulting in activity modulations or in increased susceptibility to the action of other degradative pathways (cf. Saido et al., 1994; Williams et al., 1999). Although thiol proteinase inhibitors have been proposed to be ineffective in counteracting muscle protein degradation in experimental cachexia (Temparis et al., 1994; Baracos et al., 1995), other reports have shown that 
administration of leupeptin is able to protect rats bearing the Yoshida ascites hepatoma AH130 from muscle wasting, and that $\mathrm{Ca}^{2+}$-dependent proteolysis is activated in muscles and heart of the AH-130 hosts (Costelli et al., 2001, unpublished observations). Similar observations suggesting the involvement of calpains in the pathogenesis of muscle depletion have been reported in septic rats administered dantrolene, an inhibitor of intracellular $\mathrm{Ca}^{2+}$ release; such treatment results in prevention of muscle wasting as well as of hyperexpression of calpains and of molecules pertaining to the ubiquitin-proteasome system (Williams et al., 1999; Wray et al., 2002). These reports are particularly intriguing since they propose that $\mathrm{Ca}^{2+}$-dependent proteolysis may be a necessary step to allow the release of myofibrillar proteins from the sarcomere, rendering them susceptible to degradation by the ubiquitin-proteasome system. Finally, a report has demonstrated that hyperexpression of calpastatin partially protects mice from unloaded-induced muscle atrophy (Tidball \& Spencer, 2002).

Similarly to calpains, also the caspase system, can only operate a partial proteolysis of its substrates. Caspases are a family of cysteine proteases mostly known for their role in the initiation and execution of the apoptotic process. Few years ago, some studies proposed that caspase 3 could also share with calpains the role as triggers of the initial proteolytic step needed to render myofibrillar proteins available for degradation by the proteasome. In this regard, recombinant caspase-3 has been shown to cleave actomyosin complexes, and caspase-3 inhibitors can prevent the accumulation of actin fragments in the skeletal muscles of diabetic or uremic rats (Du et al., 2004). Consistently with these observation, caspase-3 knock-out mice have been shown to be resistant to denervation-induced muscle atrophy (Plant et al., 2009). In addition, myofibrillar proteins damaged by oxidation appear more susceptible to degradation by caspase-3 (Smuder et al., 2010), while a recent study reports that caspase 3 cleaves specific proteasome subunits in myotube cultures, leading to enhanced proteasome enzymatic activity (Wang et al., 2010). Finally, muscle atrophy that occurs in Duchenne muscular dystrophy or in heart failure has been associated with reduced myonuclei number, suggesting that caspases may contribute to muscle depletion also by inducing apoptotic events (Sandri, 2002).

While several evidence support the concept that hypercatabolism is the major cause of muscle protein depletion, the trigger(s) of such enhanced metabolism remain still elusive. in this regard, humoral mediators are now widely accepted to play a crucial role. Indeed, altered production/release of classical hormones and cytokines generates a complex network that results in inhibition of anabolic and/or anticatabolic signals, favoring the degradative side of protein turnover. Consistently, the muscle wasting pattern observed in experimental and human cachexia or in aging-associated sarcopenia has been shown to be prevented by insulin administration or by local overexpression of IGF-1 (Tessitore et al., 1994; Musarò et al., 2001; Lundholm et al., 2007). On the other side, circulating glucocorticoids are frequently elevated at supraphysiological levels in several chronic pathologies, and have been shown to exert a clear catabolic effect (see Schakman et al., 2009). At least the proteasome and the lysosomaldependent proteolytic systems are susceptible of regulation by the hormonal milieu. Indeed, insulin is one of the most powerful autophagy inhibitors (Pfeifer, 1977), is able to reduce the expression of both ubiquitin and 14-kDa E2 mRNA, and to down-regulate proteasome activities (Wang et al., 2006). By contrast, glucocorticoid treatment increases the expression of ubiquitin, 14-kDa E2 and 20S proteasome subunit in rat skeletal muscle (see Schakman et al., 2009). Muscle wasting and modulations of ubiquitin expression and proteasome activities 
have also been reported in experimental animals treated with the cytokines TNF $\alpha$ or IL-1 (Tisdale, 2008). The relevance of cytokines to the onset of muscle wasting at least in cancer cachexia have been demonstrated by studies showing that loss of muscle mass, protein hypercatabolism and ubiquitin hyperexpression can be prevented by administration of antibodies against TNF $\alpha$, IFN $\gamma$ or IL-6 (reviewed in Costelli and Baccino, 2003). Consistently with these observations, perturbation in cytokine homeostasis have been reported also in cancer patients, where a positive correlation with both disease progression and mortality rate takes place (Attard-Montalto et al., 1998; Nakashima et al., 1998). In addition, proinflammatory cytokines have been shown to contribute to muscle depletion also in non-neoplastic chronic diseases. Indeed, sepsis is characterized by increased circulating levels of TNF $\alpha$, IL-1 and IL-6, that appear correlated with severity and lethality. Similarly, a shift towards the proinflammatory side of the cytokine balance has been reported in patients affected by AIDS (Kedzierska \& Crowe, 2001), likely accounting for muscle protein hypercatabolism frequently occurring in such patients before the adoption of combined anti-retroviral therapy (HAART; Mangili et al., 2006). Finally, also the sarcopenia and the loss of muscle quality that characterize aging are associated with enhanced levels of proinflammatory mediators (Lee et al., 2007).

In addition to altered protein turnover rates, modulations of the myogenic process have been proposed to contribute to the pathogenesis of muscle wasting. In this regard, one key mediator of muscle depletion, $\mathrm{TNF} \alpha$, has been reported to regulate myogenesis with opposite outcomes. Local increase of TNFa in cardiotoxin-injured muscle has been shown to promote regeneration (Chen et al. 2005), while systemic increase of TNF $\alpha$ in vivo and elevated concentrations of the cytokine in vitro inhibit skeletal myogenesis (Guttridge et al. 2000; Coletti et al. 2002; 2005). In particular, exposure of C2C12 myotube cultures to TNF $\alpha$ leads to down-regulation of both MyoD and myogenin (Guttridge et al., 2000). MyoD appears down-regulated also in a TNF $\alpha$-dependent experimental model of cancer cachexia (Costelli et al., 2005). A different study has shown that TNF $\alpha$ induces MyoD degradation through an unusual mechanism involving NFaB activation (Guttridge et al. 2000), while recently MyoD hjas been demonstrated to be a substrate of the ubiquitin ligase atrogin-1 (Tintignac et al., 2005). Down-regulation of myogenesis may also depend on impaired stem cell recruitment. In this regard, deregulation of stem cell number or activation has been shown to result in decreased muscle mass (Nicolas et al., 2005). Moreover, TNF $\alpha$ has been proposed to abrogate stem cell function, resulting in delayed or impaired muscle regeneration in mice after injury (Moresi et al., 2008). A compromised regenerative capacity has also been reported in tumor-bearing mice (Coletti et al., 2005; Penna et al., 2010a); such a pattern is associated with the appearance of hematopoietic stem cell infiltration the skeletal muscle, quantitatively more important in the tumor hosts than in controls (Coletti et al., 2005). Muscle atrophy induced in mice by aging or hindlimb suspension has also been associated with loss of muscle precursor cells, that results in reduced regenerative potential (Mitchell and Pavlath 2004).

\section{Protein kinases in the pathogenesis of skeletal muscle wasting}

Few kinase systems have been involved in the pathogenesis of muscle atrophy, the one regulated by growth factors such as insulin or IGF-1, the Mitogen Activated Protein Kinases (MAPKs), and the energy sensor AMP-activated protein kinase (AMPK). 
Insulin/IGF-1 receptors are endowed with an intrinsic tyrosine kinase activity, that is stimulated by interaction with the specific ligands. After engagement, receptor autophosphorylation allows the recruitment of IRS (insulin receptor substrate) factors. Tyrosine-phosphorylated IRS activates PI3K, producing phosphoinositide-3,4,5triphosphate (PIP3). PIP3 acts on phosphoinositide-dependent kinase 1 (PDK1), which in turn phosphorylates and activates Akt. This kinase is well known for mediating anabolic signals (see above) through the indirect activation of mTOR, that requires the inhibition of TSC (tuberous sclerosis complex). Once phosphorylated, mTOR may participate to two different protein complexes, the Raptor-containing TORC1, sensitive to inhibition by rapamycin, and the Rictor-containing TORC2, which cannot be blocked by rapamycin (reviewed in Schiaffino \& Mammucari, 2011). While the latter is required for Akt activation, mTORC1 phosphorylates p70s6K, stimulating protein synthesis. In addition to TORC1, protein synthesis induction also relies on Akt-dependent GSK3 $\beta$ inhibition, that consequently removes the blockade impinging on the elongation factor eIF-2B. Active Akt also down-regulates protein breakdown by inactivating FoxO factors, thus inhibiting the transcription of the so called 'atrogenes', among which the muscle-specific ubiquitin ligases atrogin-1 and MuRF1 (Sandri et al., 2004; Stitt et al., 2004). FoxO3, in particular, has been proposed to contribute also to the regulation of LC3, an essential actor in the hyperactivation of the autophagic-lysosomal proteolysis (Zhao et al., 2007). Akt activation is influenced by several regulative mechanisms. Indeed, it is inhibited by $\mathrm{p} 70^{56 \mathrm{~K}}$, through IRS inactivation by phosphorylation of serine residues, while it is induced by mTORC2 (see above). The PI3K/Akt pathway plays a pivotal role in modulating the skeletal muscle mass; indeed, it is upregulated in conditions characterized by muscle hypertrophy, while its disruption results in muscle atrophy (Glass, 2010). Not only, a hypertrophic phenotype occurs when Akt is hyperexpressed in skeletal muscle cells or is conditionally activated in the muscle of adult rats (Rommel et al., 2001; Lai et al., 2004). In addition, a protection against denervation-induced atrophy has been shown in transgenic mice overexpressing Akt (Bodine et al., 2001). Perturbations of the IGF-1 signaling pathway have been reported in both in vitro and in vivo models of muscle atrophy (reviewed in Glass, 2010). Indeed, the levels of active Akt are significantly reduced in C2C12 myotubes exposed to glucocorticoids or nutrient deprivation (Sandri et al., 2004). Decreased activity of the PI3K/Akt pathway has also been shown to occur in muscle wasting induced by denervation (Hornberger et al., 2001), disuse (Sugiura et al., 2005), aging (Clavel et al., 2006) or glucocorticoid treatment (Schakman et al., 2008). By contrast, levels of phosphorylated Akt in the skeletal muscle of tumor-bearing animals are comparable to controls, or even increased (Penna et al., 2010b), although a down-regulation of Akt activation has been reported in patients affected by pancreatic cancer (Schmitt et al., 2007). The maintenance of p-Akt levels in experimental cancer cachexia is particularly intriguing, since circulating IGF-1 and insulin levels are markedly reduced in the tumor-bearing animals (Costelli et al., 2006), and muscle wasting can be prevented by administration of insulin, though not of IGF-1 (Costelli et al., 2006; Tessitore et al., 1994). Akt phosphorylation mainly relies on the balance between the activity of PI3K and the phosphatases PTEN and PP2A. In particular, reduced PTEN activation has been observed in the skeletal muscle of fasted animals, likely to counteract Akt downregulation, in the attempt to preserve muscle proteins (Hu et al., 2007). However, both phosphatases are comparably expressed in the skeletal muscle of control and tumor-bearing 
animals. In addition to Akt, also other molecules involved in the regulation of protein synthesis, such as eIF2 $\alpha$, eIF-4B, p70s6K, are in an active state in the skeletal muscle of tumorbearing animals; however, previous results show that the rates of protein synthesis are not increased, but just maintained at control levels (Costelli et al., 2005, Tessitore et al., 1994). Whether this results from the lack of specific aminoacids or from activation/inactivation of other unknown mechanisms is not clear. In this regard, an inhibition of protein synthesis could result from the atrogin-1-dependent degradation of eIF-3F, a scaffold protein that coordinates both mTOR- and p70s6K-mediated translation. On the same line, protein synthesis has been proposed to be regulated by MuRF-1, independently from the PI3K/Akt pathway (Clarke et al., 2007; Koyama et al., 2008).

Four main MAPKs have been identified in mammals: JNK (1-3) and p38 $(\alpha-\delta)$, activated by stress conditions, and the extracellular signal related ERK $1 / 2$ (hereafter referred to as ERK) and ERK5, or big MAPK (Raman et al., 2007). MAPKs are activated by phosphorylation of both threonine and tyrosine residues by MAPK-kinases (MKKs) and inactivated by specific phosphatases such as the MAPK-phosphatase 1 (MKP-1; Raman et al., 2007). MAPKs are recognized as being of crucial importance in the process of myogenesis, although their role in the different steps of new fiber formation and specification still needs to be clarified. As an example, Ras-dependent ERK activation has been shown to lead to MHC-I expression, resulting in slow-fiber type differentiation (Murgia et al., 2000). These observations however, are in contrast with different studies reporting that ERK activation inhibits myotube formation (Miyake et al., 2009), while recent reports show that ERK activation is higher in fast- than in slow-twitch muscles (Shi et al., 2007) and that inhibition of MAPK signaling leads to a shift of fast fibers towards the slow-twitch phenotype (Shi et al., 2008). The activation of p38 appears required to phosphorylate substrates involved in myogenesis, as well as to induce MHC-IIx expression in myoblasts (Meissner et al., 2007). Indeed, p38 modulates the expression of myogenic regulatory factors (MRFs), such as Myf5, and the activities of transcription factors belonging to the MEF2 and MyoD families. A reciprocal regulation has been proposed to exist between p38 and ERK. While the former inhibits ERK, withdrawing myocytes from the cell cycle and enhancing muscle differentiation, ERK inhibition results in marked activation of p38 (Keren et al., 2006). In this regard, the interaction between these two kinases, likely leading to a defective activation of p38, has been proposed to play a role in the development of rhabdomyosarcoma (Puri et al., 2000). In addition to the reciprocal regulation with ERK, a cross-talk between p38 and JNK also takes place. Initially described in cardiomyocytes, it has now been demonstrated also in the skeletal muscle. In particular, p38 has been shown to antagonize the proliferative signal driven in myoblasts by JNK-dependent cyclin D1 transcription, shifting cells towards differentiation (Perdiguero et al., 2007). Consistently, p38 deficient myoblasts are characterized by a prominent JNK phosphorylation, that appears to depend, partially at least, on reduced expression of MKP-1 (Perdiguero et al., 2007). Finally, JNK has been also involved in the activation of caspases in atrophying skeletal muscles (Supinski et al., 2009).

Several situations characterized by muscle wasting, among which aging, type II diabetes, COPD, and inflammatory myopathies are associated with increased MAPK phosphorylation, p38 in particular (reviewed in Glass, 2010). Activation of p38 stimulates atrophy by enhancing the expression of atrogin-1 and MuRF1(Li et al., 2005; Romanello et al., 2010) This is also evident from in vitro experiments, showing that the increased 
expression of atrogin-1 and MuRF-1 induced by TNF-a in C2C12 myotubes as well as the induction of the ubiquitin-specific protease-19 by cigarette smoke in L6 cultures are prevented by p38 inhibitors (Li et al., 2005; Liu et al., 2011). Similarly, atrogin-1 upregulation and muscle mass depletion induced by lipopolysaccharide (LPS) in mice depend on p38 activation; indeed, such effects are inhibited by curcumin administration, that leaves intact LPS ability to modulate both NF- $\mathrm{KB}$ and Akt activity (Jin \& Li, 2007). LPS exerts its bioactivity through Toll-like receptors (TLR), in particular TLR4, expressed on both macrophages and muscle cells. Signaling through this receptor may significantly impinge on muscle protein degradation for multiple reasones: TLR4 engagement leads to p38 and NF$\mathrm{\kappa B}$ activation; this could result in the upregulation of atrogin- 1 and MuRF1 in the muscle, directly, or indirectly, through the release of proinflammatory mediators by macrophages. In addition, TLR4 has recently been involved in the activation of autophagy, increasing autophagosome formation by a p38-dependent mechanism (Doyle et al., 2011). Activation of p38 has also been shown to occur in response to mechanical or electrical stimulation, and functional overload of the skeletal muscle (Boppart et al., 2001; Huey, 2006; Sakamoto et al., 2003;), suggesting that this kinase plays a role in both anabolic and catabolic responses. Among the targets of p38 is MAPK-kinase 2 (MKK2), that appears involved in mediating p38 nuclear export (Gorog et al., 2009). MKK2 is phosphorylated by p38 at two threonine residues, both necessary for the activation (Engel et al., 1995); phosphorylation at T317 allows MKK2 export in a complex containing p38 itself (Ben-Levy et al., 1998; Meng et al., 2002). Heat shock protein 27 (HSP27, Stokoe et al., 1992), involved in the regulation of actin filament dynamics, is a substrate of MKK2 (Guay et al., 1997). Phosphorylation of HSP27 is increased in skeletal muscle hypertrophy and decreased during atrophy (Huey, 2006; Kawano et al., 2007), while HSP27 hyperexpression is able to reduce skeletal muscle depletion due to disuse (Dodd et al., 2009). Finally, MKK2 expression is reduced also in denervation-induced atrophy (Norrby and Tagerud, 2010). The occurrence of a cross-talk between MKK2/p38 and PI3K/Akt/mTor pathways has been proposed. In this regard, the MKK2/p38 complex exported from the nucleus appears to interact with a cytoplasmic HSP27/Akt complex (Wu et al., 2007). Similarly to Akt, also MKK2 can phosphorylate TSC2 and FoxO1, thus impinging on both protein synthesis and catabolism (reviewed in Rosner et al., 2008).

The involvement of ERK in the pathogenesis of skeletal muscle atrophy is quite controversial. ERK inactivation has been shown to result in muscle atrophy in the rat, irrespective of the fiber type (Shi et al., 2009), and to inhibit the hypertrophic response induced in fast muscles by treatment of the animals with $\beta_{2}$-adrenergic agonists or IGF-1 (Haddad \& Adams, 2004; Shi et al., 2007). In addition, reduced levels of phosphorylated ERK have been demonstrated in age-induced sarcopenia (Carlson et al., 2009). In C2C12 myotubes, ERK inhibition appeares required to stimulate ubiquitin ligase expression (Shi et al., 2008). Consistently, ubiquitin hyperexpression induced in L6 myotubes by glucocorticoids has been shown to depend on the activity of both MEK, the kinase upstream of ERK, and the Sp1 transcription factor (Marinovic et al., 2002). Constrasting observations have been reported, however. As an example, ERK activation in $\mathrm{C} 2 \mathrm{C} 12$ cultures has been shown to result in reduced myotube size (Rommel et al., 1999), while its inhibition leads to a hypertrophic phenotype similar to that elicited by IGF-1 (Rommel et al., 1999). On the same line, the protection exerted against oxidative stress-induced damage in both C2C12 and L6 myocytes by treatment with IGF-1 has been proposed to involve ERK activity (Yang et al., 
2010). Finally, muscle atrophy due to immobilization by hind-limb suspension has been associated with increased levels of phosphorylated ERK (Kato et al., 2002). In addition to contribute in modulating adult skeletal mass, ERK has also been involved in the myogenic process. Indeed, FGF-induced activation of ERK has been shown to enhance the regenerative capacity of human satellite cells isolated from both young and old subjects, while proliferating fusion-competent myoblasts cannot be observed when ERK is inhibited (Carlson et al., 2009). Several humoral factors, such as IGF-1, proinflammatory cytokines and myostatin can contribute to activate ERK in the skeletal muscle. In particular, recent observations from our laboratory have shown that TNF $\alpha$-induced myotube reduction in size in $\mathrm{C} 2 \mathrm{C} 12$ cultures is associated with ERK activation and increased myostatin expression (Lenk et al., 2009). Similar observation have been reported also in the skeletal muscle of tumor-bearing mice (Penna et al., 2010a). In this regard, myostatin has been previously proposed to activate ERK and to repress differentiation of $\mathrm{C} 2 \mathrm{C} 12$ myocytes (Yang et al., 2006), pointing to a causal relationship between myostatin and ERK biological activities.

Increased levels of phosphorylated JNK in the skeletal muscle are characteristically observed in conditions of insulin resistance, such as obesity or type II diabetes (Masharani et al., 2011). JNK activation mediates insulin resistance by enhancing IRS phosphorylation at serine residues, thus inhibiting the transduction of IGF-1/insulin-dependent signals (Masharani et al., 2011). Oxidative stress consequent to lipotoxicity, as well as proinflammatory mediators (cytokines and others, such as homocysteine), derived or not from the adipose tissue, likely participate in activating JNK. This latter, together with ERK and p38 MAPKs, is also activated in the skeletal muscle after exercise; such activation depends on exercise-induced oxidative stress, being prevented by treatment of healthy volunteers with the antioxidant N-acetylcysteine (Petersen et al., 2011). Both JNK and its preferential substrate c-Jun are activated in the muscle of patients with chronic kidney failure (Verzola et al., 2011). Recent reports have shown that the activation of JNK that characterizes denervation-induced muscle atrophy can be prevented by targeted ablation of the adapter protein TRAF6 (Paul et al., 2010). By contrast, no changes in the levels of phosphorylated JNK have been observed in the skeletal muscle of animals bearing experimental tumors (Penna et al., 2010a). The signal transduction pathway dependent on JNK plays a role in the apoptotic response in several cell systems (Dhanasekaran \& Reddy, 2008). In this regard, muscle injury induced by cardiotoxin injection has been shown to be initially associated with JNK activation and perturbations in the Bax/Bcl-2 system, and subsequently with classical signs of apoptotic death such as cytochrome c release from mitochondria, caspase activation, PARP cleavage (Sinha-Hikim et al., 2007). The mechanisms underlying JNK-dependent apoptosis in cardiotoxin muscle injury is still unclear, however, increased NO production through iNOS induction might be involved (Sinha-Hikim et al., 2007). Consistently with these observation, diaphragm weakness induced by endotoxin treatment has been associated with JNK phosphorylation and caspase 8 activation (Supinski et al., 2009).

Finally, quite recent evidence support a role for AMPK in the pathogenesis of skeletal muscle wasting. This kinase mainly works as a sensor of intracellular energetic balance, but is also involved in the regulation of protein turnover. AMPK is switched on when the energy state of the cell is low; in the skeletal muscle, also fiber contraction, which is an energy dissipating process, leads to AMPK activation (Mihaylova \& Shaw, 2011). The 
interference exerted by AMPK on protein synthesis is mainly related to its ability to inhibit mTOR signaling (Mihaylova \& Shaw, 2011). On the other side, AMPK has been shown to modulate protein degradation rates. Indeed, administration of AICAR, an AMPK agonist, to mice results in increased levels of phosphorylated AMPK, associated with enhanced atrogin-1 expression through a FoxO-dependent mechanism; such a pattern is inhibited by treating the animals with Compound C, an AMPK inhibitor (Nakashima et al., 2007; Romanello et al., 2010). AMPK activation has also been reported in the skeletal muscle of tumor-bearing animals (Penna et al., 2010a ; White et al., 2011), where it is associated with marked alterations of mitochondrial morphology (Penna et al., unpublished observations). The AMPK-dependent pathway links the alterations in the mitochondrial system, including reduced ATP production, with the onset of muscle atrophy. In this regard, energy deficiency could result in AMPK-dependent FoxO activation. Taking into account that FoxO transcription factors have been also involved in the regulation of autophagy, and that this latter process is in charge of sequestration and degradation of damaged organelles, FoxO activation may contribute to mitochondrial loss, further enhancing energy imbalance.

\section{Protein kinase inhibitors to prevent skeletal muscle wasting}

Muscle wasting is now well accepted to derive from metabolic alterations due to the combined action of several factors that act in a complex network involving different signal transduction pathways. The result of such networking is clearly reflected on muscle protein turnover, ultimately leading to the onset of a protein hypercatabolic state. Muscle wasting in patients affected by chronic diseases, but also in 'healthy' elderly people (sarcopenia of aging), is a highly debilitating condition, that markedly impairs quality of life, recovery from illnesses, and tolerance to therapies. The result is a significant complications in the management of these persons, also with important consequences at the social care level. In this regard, therapeutic approaches aimed at interfering pharmacologically with the onset of tissue wasting need to be pursued. On the bases of results obtained in experimental models, a number of drugs have been proposed to counteract the development of muscle wasting. Among these are protein kinase inhibitors; the rationale for their use stands up from the observations reported by several studies demonstrating that protein kinases are of crucial relevance to the activation/inactivation of mechanisms involved in the depletion/preservation of skeletal muscle mass.

About 25 years ago the first natural kinase inhibitor, namely staurosporine, able to block protein kinase $\mathrm{C}$ but also many other kinases, has been discovered. Subsequently, the specific inhibitor of p38, SB203580, has become available, opening the research of heterocyclic "drug-like" structures able to distinguish between different kinases. As an example, SB203580 binds to p38, but not to the closely related JNK (Dar and Shokat, 2011). Up to now, nine kinase inhibitors have currently been approved by the FDA (imatinib, gefitininb, sorafenib, erlotininb, sunitinib, dasatinib, nilotinib, lapatininb, pazopanib, PLX4032), however, there are many other small molecules endowed with similar properties. Most of these inhibitors bind in the ATP site, thus preventing kinase activation. The most relevant use for the inhibitors approved by FDA, mainly working as tyrosine-kinase blockers, is in the antineoplastic therapy. In this regard, imatinib, whose main target is the $\mathrm{BCR}-\mathrm{Abl}$ kinase, has been the first to be used in the treatment of chronic myelogenous 
leukemia, while sorafenib is currently administered to patients affected by renal or hepatocellular carcinoma (Dar and Shokat, 2011).

Only recently protein kinase inhibitors have been proposed as a means to counteract the onset of skeletal muscle wasting. In this regard, we have recently demonstrated that treatment of mice bearing the C26 tumor with the ERK inhibitor PD98059 partially but significantly protects tumor hosts from the onset of body weight loss and muscle mass depletion (Penna et al., 2010a). ERK inhibition also results in normalization of atrogin-1 hyperexpression, independently from the state of activation of Akt. Among the targets of ERK is the AP-1 transcription factor, which is activated in tumor-bearing animals (Costelli et al., 2005) and may contribute to muscle atrophy, since this latter is improved inhibiting AP-1 by a c-jun dominant negative (TAM67; Moore-Carrasco et al., 2006) . AP-1 regulated genes may contribute to muscle depletion; as an example, cyclin D1 expression (Moore-Carrasco et al., 2006) could induce satellite cell proliferation, that not necessarily is followed by differentiation, resulting in impaired myogenesis. The differential expression of specific factors defines the phenotype of satellite cells. In particular, while MyoD can be detected more or less throughout the myogenic process, high levels of Pax7 associated with low myogenin expression characterize proliferating satellite cells; an opposite pattern can be observed in differentiating cells (Halevy et al., 2004). Indeed, previous reports have shown that Pax7 hyperexpression results in inhibition of myogenesis (Olguin \& Olwin, 2004). Low rates of myogenesis (satellite cell activation and differentiation) participate to the maintenance of physiological skeletal muscle mass (Nicolas et al., 2005). This is confirmed by observations showing that aging- or hindlimb suspension-induced muscle atrophy is associated with a reduced regenerative potential (Mitchell \& Pavlath, 2004). Consistently, Pax7 expression is significantly increased in the muscle of C26 hosts with respect to controls, while myogenin levels are reduced. The pattern of Pax7 and myogenin expression in the C26-bearing mice is compatible with an impaired regenerative process and suggests the possibility that activated satellite cells accumulate in tumor host muscle because of either enhanced proliferation or impaired differentiation or both. Altered expression of myogenic factors has previously been reported in AH-130 hepatoma-bearing rats (Costelli et al., 2005), in cancer patients (Ramamoorthy et al., 2009), and in an experimental model of chronic kidney disease (Zhang et al., 2010). In the latter report, downregulation of IGF-1 signaling appears responsible for impaired regeneration (Zhang et al., 2010). The results obtained in our laboratory suggest an alternative mechanism based on ERK activation: when the C26 hosts are treated with PD98059, and ERK is thus inhibited, Pax7 and myogenin expression is restored to control values. These observations suggest that ERK activation likely contributes to maintain satellite cells in an undifferentiated state (Penna et al., 2010a).

Despite several reports have shown that p38 is involved in the induction of atrogenes as well as in the hyperactivation of protein degradation in different model systems, there are no studies demonstrating that its pharmacological inhibition in experimental animals may protect the skeletal muscle from wasting. In this regard, we have tested the effectiveness of the p38 inhibitor SB203580 in preventing skeletal muscle depletion in animals implanted with the C26 tumor. After a subcutaneous inoculum of about $10^{6}$ C26 cells, death of the animals occurs in about 15 days; tumor growth is associated with progressive loss of body weight, depletion of both the skeletal muscle and the adipose tissue mass, as well as with markedly increased circulating levels of IL-6 (Penna et al., 2010a). Control and tumor- 
bearing mice have been treated daily with subcutaneous injection of 3 or $30 \mathrm{mg} / \mathrm{kg}$ initial body weight of SB203580, dissolved in DMSO and then diluted in saline, starting from the day after tumor implantation. No significant differences could be observed as for both muscle force (evaluated by grasping test; Fig. 1A), food intake (Fig. 1B) and tumor mass (C26: $231 \pm 93 \mathrm{mg}, \mathrm{C} 26+$ SB203580 $30 \mathrm{mg} / \mathrm{kg}: 249 \pm 31 \mathrm{mg}$ ). By contrast, an increase of body weight occurred in the group of tumor bearers that received SB203580 at the dose of 30 $\mathrm{mg} / \mathrm{kg}$ when compared to both treated or untreated controls (Fig.1C). Body weight accretion, however, does not reflect an effect on the skeletal muscle mass, that remains close to the values of untreated tumor hosts, while the weight of both liver and spleen is significantly higher in treated than in untreated C26 bearers, possibly reflecting drug toxicity (Fig. 1D).

A

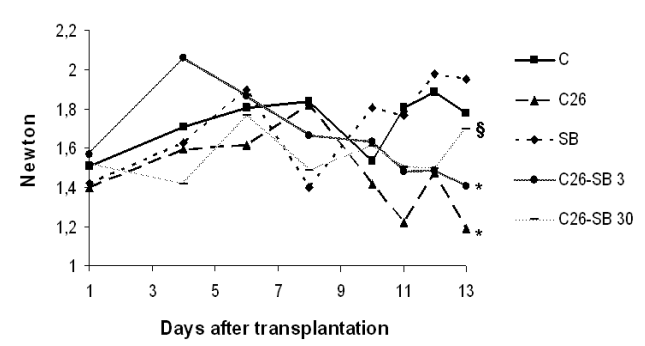

C

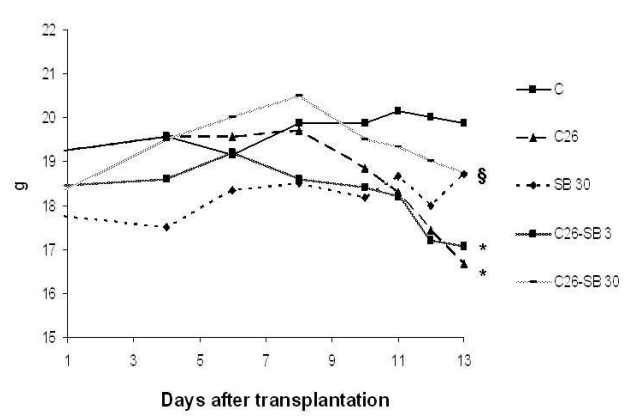

B Food intake

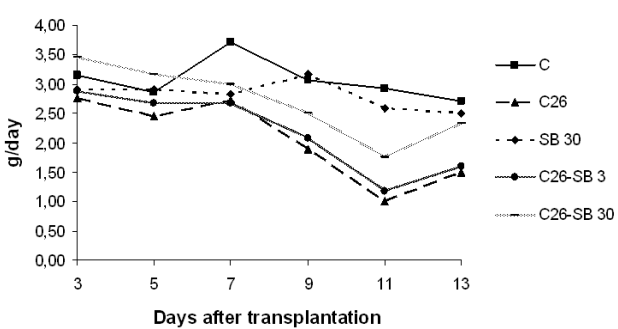

D Muscle and tissue weight

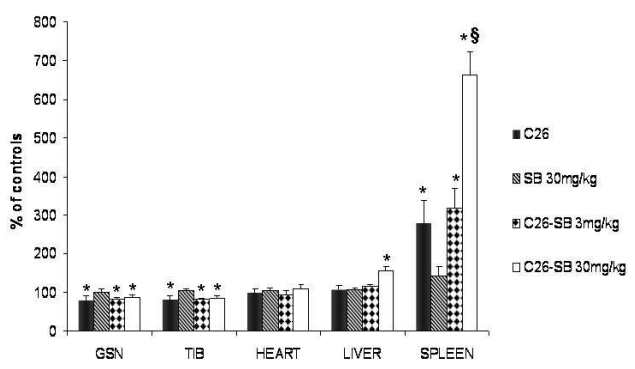

(A): voluntary muscle strength, evaluated by dynamometer, expressed in Newton; (B) food intake, expressed as the means amount of food (g) consumed be the animals every two days; (C) body weight (g), inclusive of the tumor; (D) muscle and tissue weight, expressed as percentages of controls. Date are represented as means $\pm \mathrm{SD}$ (where not indicated SD is within $10 \%$ of the means), $\mathrm{n}=8$ for each experimental group. Significance of the differences: * $p<0.05$ vs. untreated controls, $\& p<0.05$ vs. untreated C26 hosts.

Fig. 1. Effect of treatment with SB203580 on cachexia in mice bearing the C26 colon carcinoma. 
The results obtained by treating the C26 hosts with SB203580 could sound unexpected, since p38 has been shown to be involved in different mechanisms contributing to skeletal muscle depletion (see above). However, when analyzing the state of activation of MAPKs in two different experimental models, namely rats bearing the AH-130 hepatoma and the C26 hosts, just ERK appears phosphorylated (active; Penna et al., 2010a), suggesting that the usual pattern of p38 involvement in muscle wasting likely does not apply to cancer cachexia. The other way round, p38 inhibition could have lead to a differential modulation of the mechanisms impinging on cancer-associated muscle wasting, mainly protein hypercatabolism and impaired myogenesis, worsening the latter and improving the former, or vice versa, resulting in lack of changes of muscle mass. Further work is warranted to clarify this point.

Finally, imatinib mesylate (IM) administration has been shown to improve muscle pathology in mdx mice, an accepted model for the Duchenne-type muscle dystrophy. In particular, IM-treated mice show a less degree of muscle necrosis, inflammation and fibrosis than control animals. Such effects appear to depend on the inhibition exerted by the drug on the activation of both c-Abl and PDGFR on both peritoneal macrophages and muscleresident fibroblasts (Huang et al., 2009). Similar observations have been independently reported by another group (Bizario et al., 2009). Both reports suggest that treatment with IM exerts a marked anti-inflammatory effect, lowering the levels of proinflammatory cytokines. Keeping this in mind, we decided to test the effectiveness of IM in preventing muscle wasting in cancer cachexia, where the role played by the inflammatory state is widely accepted. The above cited C26 model has been used. IM has been administered with daily subcutaneous injection at the concentration of $400 \mathrm{mg} / \mathrm{kg}$ initial body weight, dissolved in water. Food intake have been recorded daily. At day 15 the animals have been sacrificed to evaluate the effects exerted by the treatment on body and tissue weight. The data reported in Figure 2 show that IM does not induce any detectable modifications when administered to healthy mice, demonstrating that the drug itself does not exert toxic effects on the animals. The treatment, however, is not able to correct the wasting pattern caused by the growth of the C26 tumor. Indeed, loss of body weight (Fig. 2A), cumulative food intake reduction (Fig. 2B), and mass depletion of gastrocnemius, tibialis anterior and heart (Fig. 2C) are comparable between treated and untreated tumor hosts. By contrast, spleen hypertrophy, a constant finding in the C26 hosts (Penna et al., unpublished observations; Fig. 1D, 2C), is completely prevented by treatment with IM (Fig. 2C), confirming the antiinflammatory effect of this drug. Finally, no significant differences could be observed as for tumor mass between mice administered IM or vehicle (C26: 325 $\pm 86 \mathrm{mg}$, C26+IM: $253 \pm 79 \mathrm{mg}$, not statistically significant).

The results show that while able to improve muscle phenotype in mdx mice (Bizario et al., 2009; Huang et al., 2009), IM is ineffective in preventing muscle wasting in tumor-bearing animals, although it likely exert an anti-inflammatory action, as shown by the protection against spleen hypertrophy. These observations may suggest that the tyrosine kinases blocked by IM might not be involved in the pathogenesis of muscle wasting in cancer cachexia. However, the lack of effect could also depend on the different inflammatory situation occurring in the muscle of mdx mice and of tumor-bearing animals. Indeed, while the former is characterized by a marked inflammatory infiltrate, associated with an important fibrotic response, these alterations are quite lacking in the latter. 

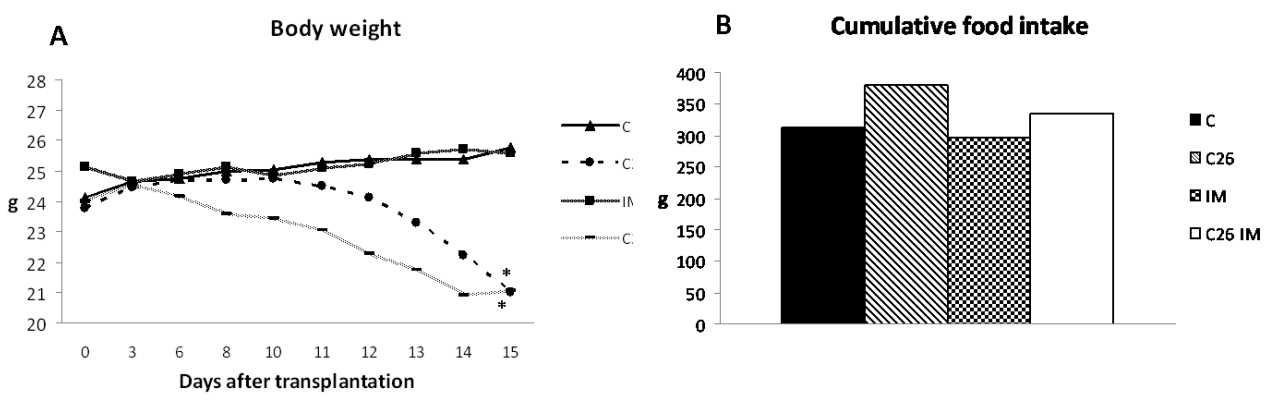

C

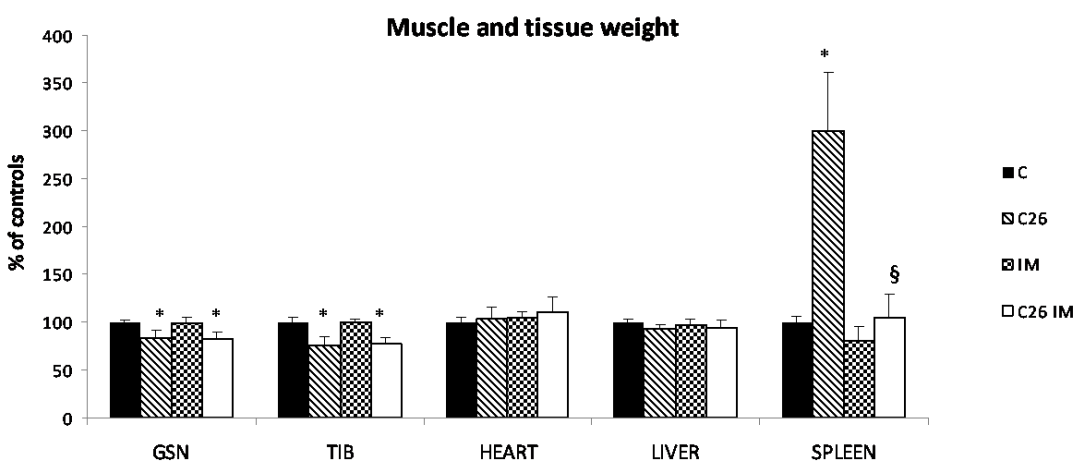

(A): body weight (g), inclusive of the tumor; (B) cumulative food intake (g) over the whole experimental period; (C) muscle and tissue weight, expressed as percentages of controls. Date are represented as means $\pm S D$ (where not indicated SD is within $10 \%$ of the means), $n=8$ for each experimental group. Significance of the differences: ${ }^{*} \mathrm{p}<0.05$ vs. untreated controls, § $\mathrm{p}<0.05$ vs. untreated C26 hosts.

Fig. 2. Effect of treatment with imatinib mesylate (IM) on cachexia in mice bearing the C26 colon carcinoma.

\section{Conclusions}

Evidence coming from different experimental models have demonstrated the possibility to interfere with the onset of muscle protein hypercatabolism by several means, such as exercise, nutritional, and pharmacological interventions, better if combined. The growing amount of knowledge about the mechanisms underlying the alterations of muscle protein metabolism are highly relevant in this regard. Particular attention deserves the observation that several experimental results point to kinases as crucially involved in the activation/enhancement of the mechanisms leading to skeletal muscle depletion, either in physiological or pathological states. On this line, the availability of specific kinase inhibitors has opened the way to a direct evaluation of their possibility to be used as therapeutic tools to treat conditions characterized by skeletal muscle wasting. At present the results available in the literature are very few, and at least some of them appear encouraging. However, a note of care should be introduced, since inhibiting protein kinases would also impinge on transduction pathways physiologically relevant, rendering unavoidable an accurate estimate of the risk/benefit ratio. 


\section{References}

Adamo, M.L. \& Farrar, R.P. (2006). Resistance training, and IGF involvement in the maintenance of muscle mass during the aging process. Ageing Res Rev, Vol. 5, No. 3 (Aug), pp. 310-31, 1568-1637

Anthony, J.C., Yoshizawa, F., Anthony, T.G., Vary, T.C., Jefferson, L.S. \& Kimball, S.R. (2000). Leucine stimulates translation initiation in skeletal muscle of postabsorptive rats via a rapamycin-sensitive pathway. J Nutr, Vol. 130, No. 10 (Oct), pp. 24132419, 0022-3166

Attard-Montaldo, S.P., Camacho-Hubner, C., Cotteril, A.M., D'Souza-Li, L., Bartlett, K., Halliday, D. \& Eden, O.B. (1998). Changes in protein turnover, IGF-I and IGF binding proteins in children with cancer. Acta Pediatr, Vol. 87, No. 1, pp. 54-60, 0803-5253

Baracos, V.E., DeVivo, C., Hoyle, D.H. \& Goldberg, A.L. (1995). Activation of the ATPubiquitin-proteasome pathway in skeletal muscle of cachectic rats bearing a hepatoma. Am J Physiol Endocrinol Metab, Vol. 268, No. 5, pp. E996-E1006, 0193-1849

Bassel-Duby, R. \& Olson, E.N. (2006). Signaling pathways in skeletal muscle remodeling. Annu Rev Biochem, Vol. 75, pp.19-37, 0066-4154.

Bechet, D., Tassa, A., Taillandier, D., Combaret, L. \& Attaix, D. (2005). Lysosomal proteolysis in skeletal muscle. Int J Biochem Cell Biol, Vol. 37, No. 10 (Oct), pp. 2098-2114, 13572725

Ben-Levy, R., Hooper, S., Wilson, R., Paterson, H.F. \& Marshall, C.J. (1998). Nuclear export of the stress-activated protein kinase p38 mediated by its substrate MAPKAP kinase-2. Curr Biol, Vol. 8, No. 19 (Sep 24), pp. 1049-1057, 0960-9822.

Bizario, J.C., Cerri, D.G., Rodrigues, L.C., Oliveira, G.L., Nomizo, A., de Araujo, D.D., Fukuhara, P.S., Ribeiro, J.C., de Castro, F.A. \& Costa, M.C. (2009). Imatinib mesylate ameliorates the dystrophic phenotype in exercised $\mathrm{mdx}$ mice. JNeuroimmunol, Vol. 212, No. 1-2 (Jul), pp. 93-101, 0165-5728

Bodine, S.C., Stitt, T.N., Gonzalez, M., Kline, W.O., Stover, G.L., Bauerlein, R., Zlotchenko, E., Scrimgeour, A., Lawrence, J.C., Glass, D.J. \& Yancopoulos, G.D. (2001). $\mathrm{Akt} / \mathrm{mTOR}$ pathway is a crucial regulator of skeletal muscle hypertrophy and can prevent muscle atrophy in vivo. Nat Cell Biol, Vol. 3, No. 11 (Nov), pp. 1014$1019,1465-7392$

Boppart, M.D., Hirshman, M.F., Sakamoto, K., Fielding, R.A. \& Goodyear, L.J. (2001). Static stretch increases c-Jun NH2-terminal kinase activity and p38 phosphorylation in rat skeletal muscle. Am J Physiol Cell Physiol, Vol. 280, No. 2 (Feb), pp. C352-C358, 03636143

Cai, D., Frantz, J.D., Tawa, N.E., Melendez, P.A., Oh, B.-C., Lidov, H.G.W., Hasselgren, P.O., Frontera, W.R., Lee, J., Glass, D.J. \& Shoelson, S.E. (2004). IKK $\beta / N F-\kappa B$ activation causes severe muscle wasting in mice. Cell, Vol. 119, No. 2 (Oct), pp. 285298, 0092-8674

Carlson, M.E., Suetta, C., Conboy, M.J., Aagaard, P., Mackey, A., Kjaer, M. \& Conboy, I. (2009). Molecular aging and rejuvenation of human muscle stem cells. EMBO Mol Med, Vol. 1, No. 8-9 (Nov), pp. 381-391, 1757-4676

Chen, S.E., Gerken, E., Zhang, Y., Zhan, M., Mohan, R.K., Li, A.S., Reid, M.B. \& Li, Y.P. (2005). Role of TNF-\{alpha\} signaling in regeneration of cardiotoxin-injured muscle. Am J Physiol Cell Physiol, Vol. 289, No. 5 (Nov), pp. C1179-1187, 0363-6143 
Choudry, H.A., Pan, M., Karinch, A.M. \& Souba, W,W. (2006). Branched-chain amino acidenriched nutritional support in surgical and cancer patients. J Nutr, Vol. 136, No. 1 Suppl (Jan), pp. 314S-318S, 0022-3166

Clarke, B.A., Drujan, D., Willis, M.S., Murphy, L.O., Corpina, R.A., Burova, E., Rakhilin, S.V., Stitt, T.N., Patterson, C., Latres, E. \& Glass, D.J. (2007). The E3 Ligase MuRF1 degrades myosin heavy chain protein in dexamethasone-treated skeletal muscle. Cell Metab, Vol. 6, No. 5 (Nov), pp. 376-385, 1550-4131

Clarke, I.J. \& Henry, B.A. (2010). Targeting energy expenditure in muscle as a means of combating obesity. Clin Exp Pharmacol Physiol, Vol. 37, No. 1 (Jan), pp. 121-124, 0305- 1870

Clavel, S., Coldefy, A.S., Kurkdjian, E., Salles, J., Margaritis, I. \& Derijard, B. (2006). Atrophy-related ubiquitin ligases, atrogin-1 and MuRF1 are up-regulated in aged rat Tibialis Anterior muscle. Mech Ageing Dev, Vol.127, No. 10 (Oct), pp. 794-801, 0047-6374

Codogno, P. \& Meijer, A.J. (2005). Autophagy and signaling: their role in cell survival and cell death. Cell Death Differ, Vol. 12, No. 2 Suppl (Nov), pp. 1509- 1518, 1350-9047

Coletti, D., Yang, E., Marazzi, G., \& Sassoon, D. (2002). TNFalpha inhibits skeletal myogenesis through a PW1-dependent pathway by recruitment of caspase pathways. EMBO J, Vol. 21, No. 4 (Feb), pp. 631-642, 0261-4189

Coletti, D., Moresi, V., Adamo, S., Molinaro, M. \& Sassoon, D. (2005). Tumor necrosis factoralpha gene transfer induces cachexia and inhibits muscle regeneration. Genesis, Vol. 43, No. 3 (Nov), pp. 120-128, 1526-954X

Costelli, P., De Tullio, R., Baccino, F.M. \& Melloni, E. (2001). Activation of $\mathrm{Ca}(2+)$-dependent proteolysis in skeletal muscle and heart in cancer cachexia. Br J Cancer, Vol. 84, No. 7 (Apr), pp. 946-950, 0007-0920

Costelli, P. \& Baccino, F.M. (2003). Mechanisms of skeletal muscle depletion in wasting syndromes: role of the ATP-ubiquitin-dependent proteolysis. Curr Op Clin Nutr Metab Care, Vol. 6, No. 4 (Jul), pp. 407-412, 1363-1950

Costelli, P., Muscaritoli, M., Bossola, M., Moore-Carrasco, R., Crepaldi, S., Grieco, G., Autelli, R., Bonelli, G., Pacelli, F., Lopez-Soriano, F.J., Argilés, J.M., Doglietto, G.B., Baccino, F.M. \& Rossi Fanelli, F. (2005). Skeletal muscle wasting in tumor-bearing rats is associated with MyoD down-regulation. Int J Oncol, Vol. 26, No. 6 (Jun), pp. 663-1668, 1019-6439

Costelli, P., Muscaritoli, M., Bossola, M., Penna, F., Reffo, P., Bonetto, A., Busquets, S., Bonelli, G., Lopez-Soriano, F.J., Doglietto, G.B., Argilés, J.M., Baccino, F.M. \& Rossi Fanelli, F. (2006). IGF-1 is downregulated in experimental cancer cachexia. Am J Physiol Regul Integr Comp Physiol, Vol. 291, No. 3 (Sep), pp. R674-R683, 0363-6119

Dar, A.C. \& Shokat, K.M. (2011). The evolution of protein kinase inhibitors from antagonists to agonists of cellular signaling. Annu Rev Biochem, Vol. 80, No. 7 (Jun), pp. 769795, 0066-4154

Deval, C., Mordier, S., Obled, C., Bechet, D., Combaret, L., Attaix, D. \& Ferrara, M. (2001). Identification of cathepsin $\mathrm{L}$ as a differentially expressed message associated with skeletal muscle wasting. Biochem J, Vol. 360, No. 15 (Nov), pp. 143-150, 0264-6021

Dhanasekaran, D.N. \& Reddy, E.P. (2008). JNK signaling in apoptosis. Oncogene, Vol. 27, No. 48 (Oct), pp. 6245-6251, 0950-9232 
Dodd, S.L., Hain, B., Senf, S.M. \& Judge, A.R. (2009). Hsp27 inhibits IKKbeta-induced NFkappaB activity and skeletal muscle atrophy. FASEB J, Vol. 23, No. 10 (Oct), pp. 3415-3423, 0892- 6638

Doyle, A., Zhang, G., Abdel Fattah, E.A., Eissa, N.T. \& Li, Y.P. (2011). Toll-like receptor 4 mediates lipopolysaccharide-induced muscle catabolism via coordinate activation of ubiquitin- proteasome and autophagy-lysosome pathways. FASEB J, Vol. 25, No. 1 (Jan), pp. 99-110, 0892-6638

Du, J., Wang, X., Miereles, C., Bailey, J.L., Debigare, R., Zheng, B., Price, S.R. \& Mitch, W.E. (2004). Activation of caspase-3 is an initial step triggering accelerated muscle proteolysis in catabolic conditions. J Clin Invest, Vol. 113, No. 1 (Jan), pp. 115-123, 0021-9738

Dunn, S.E., Burns, J.L. \& Michel, R.N. (1999). Calcineurin is required for skeletal muscle hypertrophy. J Biol Chem, Vol. 274, No. 31 (Jul), pp. 21908-21912, 0021-9258

Fang, C.H., Li, B.G., James, J.H., King, J.K., Evenson, A.R., Ward, G.D. \& Hasselgren, P.O. (2005). Protein breakdown in muscle from burned rats is blocked by insulin-like growth factor I and glycogen synthase kinase-3 beta inhibitors. Endocrinology, Vol. 146, No. 7 (Jul), pp. 3141-3149, 0013-7227

Engel, K., Schultz, H., Martin, F., Kotlyarov, A., Plath, K., Hahn, M., Heinemann, U. \& Gaestel, M. (1995). Constitutive activation of mitogen-activated protein kinaseactivated protein kinase 2 by mutation of phosphorylation sites and an A-helix motif. J Biol Chem, Vol. 270, No. 45 (Nov), pp. 27213-27221, 0021-9258

Glass, D.J. (2010). Signaling pathways perturbing muscle mass. Curr Opin Clin Nutr MetabCare, Vol. 13, No. 3 (May), pp. 225-229, 1363-1950

Gorog, D.A., Jabr, R.I., Tanno, M., Sarafraz, N., Clark, J.E., Fisher, S.G., Cao, X.B., Bellahcene, M., Dighe, K., Kabir, A.M., Quinlan, R.A., Kato, K., Gaestel, M., Marber, M.S. \& Heads, R.J. (2009). MAPKAPK-2 modulates p38-MAPK localization and small heat shock protein phosphorylation but does not mediate the injury associated with p38-MAPK activation during myocardial ischemia. Cell Stress Chaperones, Vol. 14, No. 5 (Sep), pp. 477-489, 1355- 8145

Greenbaum, L.M. \& Sutherland, J.H. (1983). Host cathepsin D response to tumor in the normal and pepstatin-treated mouse. Cancer Res, Vol. 43, no. 6 (Jun), pp. 2584-2587, 0008-5472

Guay, J., Lambert, H., Gingras-Breton, G., Lavoie, J.N., Huot, J. \& Landry, J. (1997). Regulation of actin filament dynamics by p38 map kinase-mediated phosphorylation of heat shock protein 27. J Cell Sci, Vol. 110, No. Pt3 (Feb), pp. 357368, 0021-9533

Guttridge, D.C., Mayo, M.W., Madrid, L.V., Wang, C.Y. \& Baldwin, A.S. Jr. (2000). NFkappaB- induced loss of MyoD messenger RNA: possible role in muscle decay and cachexia. Science, Vol. 289, No. 5488 (Sep), pp. 2363-2366, 0036-8075

Haddad, F. \& Adams, G.R. (2004). Inhibition of MAP/ERK kinase prevents IGF-I-induced hypertrophy in rat muscles. J Appl Physiol, Vol. 96, No. 1 (Jan), pp. 203-210, 87507587

Halevy, O., Piestun, Y., Allouh, M.Z., Rosser, B.W., Rinkevich, Y., Reshef, R., Rozenboim, I., Wleklinski-Lee, M. \& Yablonka-Reuveni, Z. (2004). Pattern of Pax7 expression during myogenesis in the posthatch chicken establishes a model for satellite cell differentiation and renewal. Dev Dyn, Vol. 231, No. 3 (Nov), pp. 489-502, 1058-8388 
Hanada, M., Feng, J. \& Hemmings, B.A. (2004). Structure, regulation and function of PKB/AKT - a major therapeutic target. Biochim. Byophis. Acta, Vol. 1697, No. 1-2 (Mar), pp. 3-16, 0304- 4165

Hornberger, T.A., Hunter, R.B., Kandarian, S.C. \& Esser, K.A. (2001). Regulation of translation factors during hindlimb unloading and denervation of skeletal muscle in rats. Am J Physiol Cell Physiol, Vol. 281, No. 1 (Jul), pp. C179-C187, 0363-6143

$\mathrm{Hu}$, Z., Lee, I.H., Wang, X., Sheng, H., Zhang, L., Du, J. \& Mitch, W.E. (2007). PTEN expression contributes to the regulation of muscle protein degradation in diabetes. Diabetes, Vol. 56, No. 10 (Oct), pp. 2449-2456, 0012-1797.

Huang, P., Zhao, X.S., Fields, M., Ransohoff, R.M. \& Zhou, L. (2009). Imatinib attenuates skeletal muscle dystrophy in mdx mice. FASEB J, Vol. 23, No. 8 (Aug), pp. 25392548, 0892-6638

Huey, K.A. (2006). Regulation of HSP25 expression and phosphorylation in functionally overloaded rat plantaris and soleus muscles. J Appl Physiol, Vol. 100, No. 2 (Feb), pp. 451- 456, 8750-7587

Kadowaki, M. \& Kanazawa, T. (2003). Amino acids as regulators of proteolysis. J Nutr, Vol. 133 No. 6 Suppl (Jun), pp. 2052S-2056S, 0022-3166

Kato, K., Ito, H., Kamei, K., Iwamoto, I. \& Inaguma, Y. (2002). Innervation-dependent phosphorylation and accumulation of alphaB-crystallin and Hsp27 as insoluble complexes in disused muscle. FASEB J, Vol. 16, No. 11 (Sep), pp. 1432-1434, 08926638

Kawano, F., Matsuoka, Y., Oke, Y., Higo, Y., Terada, M., Wang, X.D., Nakai, N., Fukuda, H., Imajoh-Ohmi, S. \& Ohira, Y. (2007). Role(s) of nucleoli and phosphorylation of ribosomal protein S6 and/or HSP27 in the regulation of muscle mass. Am J Physiol Cell Physiol, Vol. 293, No. 1 (Jul), pp. C35-C44, 0363-6143

Kedzierska, K. \& Crowe, S.M. (2001). Cytokines and HIV-1: interactions and clinical implications. Antivir Chem Chemother, Vol. 12, No. 3 (May), pp. 133-135, 0956-3202

Keren, A., Tamir, Y. \& Bengal, E. (2006). The p38 MAPK signaling pathway: a major regulator of skeletal muscle development. Mol Cell Endocrinol, Vol. 252, No. 1-2 (Jun), pp. 224-230, 0303- 7207

Kipreos, E.T. \& Pagano, M. (2000). The F-box protein family. Genome Biol, Vol.1, No. 5, REVIEWS3002, 1474-7596

Klionsky, D.J., Cregg, J.M., Dunn, W.A.Jr., Emr, S.D., Sakai, Y., Sandoval, I.V., Sibirny, A., Subramani, S., Thumm, M., Veenhuis, M. \& Ohsumi, Y. (2003). A unified nomenclature for yeast autophagy-related genes. Dev Cell, Vol. 5, No. 4 (Oct), pp. 539-545, 1534-5807

Koyama, S., Hata, S., Witt, C.C., Ono, Y., Lerche, S., Ojima, K., Chiba, T., Doi, N., Kitamura, F., Tanaka, K., Abe, K., Witt, S.H., Rybin, V., Gasch, A., Franz, T., Labeit, S. \& Sorimachi, H. (2008). Muscle RING-finger protein-1 (MuRF1) as a connector of muscle energy metabolism and protein synthesis. J Mol Biol, Vol. 376, No. 5 (Mar), pp. 1224-1236, 0022- 2836

Jagoe, R.T., Redfern, C.P., Roberts, R.G., Gibson, G.J. \& Goodship, T.H. (2002). Skeletal muscle mRNA levels for cathepsin B, but not components of the ubiquitinproteasome pathway, are increased in patients with lung cancer referred for thoracotomy. Clin Sci (Lond), Vol. 102, No. 3 (Mar), pp. 353-361, 0143-5221 
Jin, B. \& Li, Y.P. (2007). Curcumin prevents lipopolysaccharide-induced atrogin-1/MAFbx upregulation and muscle mass loss. J Cell Biochem, Vol. 100, No. 4 (Mar), pp. 960969, 0730- 2312

Jope, R.S. (2003). Lithium and GSK-3: one inhibitor, two inhibitory actions, multiple outcomes. Trends Pharmacol Sci, Vol . 24, No. 9 (Sep), pp. 441-443, 0165-6147

Lai, K.-M., Gonzalez, M., Poueymirou, W.T., Kline, W.O., Na, E., Zlotchenko, E., Stitt, T.N., Economides, A.N., Yancopoulos, G.D. \& Glass, D.J. (2004). Conditional activation of akt in adult skeletal muscle induces rapid hypertrophy. Mol Cell Biol, Vol. 24, No. 21 (Nov), pp. 9295-9304, 0270-7306

Frost, R.A. \& Lang, C.H. (2005). Skeletal muscle cytokines: regulation by pathogenassociated molecules and catabolic hormones. Curr Opin Clin Nutr Metab Care, Vol. 8, No. 3 (May), pp. 255-263, 1363-1950

Lecker, S.H., Jagoe, R.T., Gilbert, A., Gomes, M., Baracos, V., Bailey, J., Price, S.R., Mitch, W.E. \& Goldberg, A.L. (2004). Multiple types of skeletal muscle atrophy involve a common program of changes in gene expression. FASEB J, Vol. 18, No. 1 (Jan), pp. 39-51, 0892-6638

Lee, C.E., McArdle, A. \& Griffiths, R.D. (2007). The role of hormones, cytokines and heat shock proteins during age-related muscle loss. Clin Nutr, Vol. 26, No. 5 (Oct), pp. 524-534, 0261- 5614

Lenk, K., Schur, R., Linke, A., Erbs, S., Matsumoto, Y., Adams, V. \& Schuler, G. (2009). Impact of exercise training on myostatin expression in the myocardium and skeletal muscle in a chronic heart failure model. Eur J Heart Fail, Vol. 11, No. 4 (Apr), pp. 342-348, 1388-9842

Li, Y.P., Chen, Y., John, J., Moylan, J., Jin, B., Mann, D.L. \& Reid, M.B. (2005). TNF-alpha acts via p38 MAPK to stimulate expression of the ubiquitin ligase atrogin1/MAFbx in skeletal muscle. FASEB J, Vol. 19, No. 3 (Mar), pp. 362-370, 0892-6638

Liu, Q., Xu, W.G., Luo, Y., Han, F.F., Yao, X.H., Yang, T.Y., Zhang, Y., Pi, W.F. \& Guo, X.J. (2011). Cigarette smoke-induced skeletal muscle atrophy is associated with upregulation of USP-19 via p38 and ERK MAPKs. J Cell Biochem, Vol. 112, No. 9 (Sep), pp. 2307-2316, 0730-2312

Lundholm, K., Körner, U., Gunnebo, L., Sixt-Ammilon, P., Fouladiun, M., Daneryd, P. \& Bosaeus, I. (2007). Insulin treatment in cancer cachexia: effects on survival, metabolism, and physical functioning. Clin Cancer Res, Vol. 13, No. 9 (May), pp. 2699-2706, 1078-0432

Mammucari, C., Milan, G., Romanello, V., Masiero, E., Rudolf, R., Del Piccolo, P., Burden, S.J., Di Lisi, R., Sandri, C., Zhao, J., Goldberg, A.L., Schiaffino, S. \& Sandri, M. (2007). FoxO3 controls autophagy in skeletal muscle in vivo. Cell Metab, Vol. 6, No. 6 (Dec), pp. 458-471, 1550-4131

Mangili, A., Murman, D.H., Zampini, A.M. \& Wanke, C.A. (2006). Nutrition and HIV infection: review of weight loss and wasting in the era of highly active antiretroviral therapy from the nutrition for healthy living cohort. Clin Infect Dis, Vol. 42, No. 6 (Mar), pp. 836-842, 1058-4838

Marinovic, A.C., Zheng, B., Mitch, W.E. \& Price, S.R. (2002). Ubiquitin (UbC) expression in muscle cells is increased by glucocorticoids through a mechanism involving Sp1 and MEK1. J Biol Chem,Vol. 277, No. 19 (May), pp. 16673-16681, 0021-9258 
Masharani, U.B., Maddux, B.A., Li, X., Sakkas, G.K., Mulligan, K., Schambelan, M., Goldfine, I.D. \& Youngren, J.F. (2011). Insulin resistance in non-obese subjects is associated with activation of the JNK pathway and impaired insulin signaling in skeletal muscle. PLoS One, Vol. 6, No. 5 (May), e19878, 1932-6203

Meissner, J.D., Chang, K.C., Kubis, H.P., Nebreda, A.R., Gros, G. \& Scheibe, R.J. (2007). The p38alpha/beta mitogen-activated protein kinases mediate recruitment of CREBbinding protein to preserve fast myosin heavy chain IId/ $x$ gene activity in myotubes. J Biol Chem, Vol. 282, No. 10 (Mar), pp. 7265-7275, 0021-9258

Meng, W., Swenson, L.L., Fitzgibbon, M.J., Hayakawa, K., Ter Haar, E., Behrens, A.E., Fulghum, J.R. \& Lippke, J.A. (2002). Structure of mitogen-activated protein kinaseactivated protein (MAPKAP) kinase 2 suggests a bifunctional switch that couples kinase activation with nuclear export. J Biol Chem, Vol. 277, No. 40 (Oct), pp. 3740137405, 0021-9258

Mihaylova, M.M. \& Shaw, R.J. (2011). The AMPK signalling pathway coordinates cell growth, autophagy and metabolism. Nat Cell Biol, Vol. 13, No. 9 (Sep), pp. 1016$1023,1465-7392$

Miyake, T., Alli, N.S., Aziz, A., Knudson, J., Fernando, P., Megeney, L.A. \& McDermott, J.C. (2009). Cardiotrophin-1 maintains the undifferentiated state in skeletal myoblasts. J Biol Chem, Vol. 284, No. 29 (Jul), pp. 19679-19693, 0021-9258

Mitchell, P.O. \& Pavlath, G.K. (2004). Skeletal muscle atrophy leads to loss and dysfunction of muscle precursor cells. Am J Physiol Cell Physiol,Vol. 287, No. 6 (Dec), pp. C1753C1762, 0363-6143

Mizushima, N., Yamamoto, A., Matsui, M., Yoshimori, T. \& Ohsumi, Y. (2004). In vivo analysis of autophagy in response to nutrient starvation using transgenic mice expressing a fluorescent autophagosome marker. Mol Biol Cell, Vol. 15, No. 3 (Mar), pp. 1101-1111, 1059- 1524

Moore-Carrasco, R., Garcia-Martinez, C., Busquets, S., Ametller, E., Barreiro, E., LópezSoriano, F.J. \& Argilés, J.M. (2006). The AP-1/CJUN signaling cascade is involved in muscle differentiation: implications in muscle wasting during cancer cachexia. FEBS Lett, Vol. 580, No. 2 (Jan), pp. 691-696, 0014-5793

Morel, J,E, \& Pinset-Härström, I. (1975). Ultrastructure of the contractile system of striated skeletal muscle and the processes of muscular contraction. I. Ultrastructure of the myofibril and source of energy. Biomedicine, Vol. 22, No. 2 (Mar), pp. 88-96, 09702067

Moresi, V., Pristera, A., Scicchitano, B.M., Molinaro, M., Teodori, L., Sassoon, D, Adamo, S. \& Coletti, D. (2008). Tumor necrosis factor-alpha inhibition of skeletal muscle regeneration is mediated by a caspase-dependent stem cell response. Stem Cells, Vol. 26, No. 4 (Apr), pp. 997-1008, 1066-5099

Morgan, J.E. \& Partridge, T.A. (2003). Muscle satellite cells. Int J Biochem Cell Biol, Vol. 35, No. 8 (Aug), pp. 1151-1156, 1357-2725

Murgia, M., Serrano, A.L., Calabria, E., Pallafacchina, G., Lomo, T. \& Schiaffino, S. (2000). Ras is involved in nerve-activity-dependent regulation of muscle genes. Nat Cell Biol, Vol. 2, No. 3 (Mar), pp. 142-147, 1465-7392

Musarò, A., McCullagh, K.J., Naya, F.J., Olson, E.N. \& Rosenthal, N. (1999). IGF-1 induces skeletal myocyte hypertrophy through calcineurin in association with GATA-2 and NF-ATc1. Nature, Vol. 400, No. 6744 (Ago), pp. 581-585, 0028-0836 
Musarò, A., McCullagh, K., Paul, A., Houghton, L., Dobrowolny, G., Molinaro, M., Barton, E.R., Sweeney, H.L. \& Rosenthal, N. (2001). Localized Igf-1 transgene expression sustains hypertrophy and regeneration in senescent skeletal muscle. Nat Genet, Vol. 27, No. 2 (Feb), pp. 195-200, 1061-4036

Nakashima, J., Tachibana, M., Ueno, M., Miyajima, A., Baba, S. \& Murai, M. (1998). Association between tumor necrosis factor in serum and cachexia in patients with prostate cancer. Clin Cancer Res, Vol. 4, No. 7 (Jul), pp. 1743-1748, 1078-0432

Nicolas, N., Marazzi, G., Kelley, K. \& Sassoon, D. (2005). Embryonic deregulation of muscle stress signaling pathways leads to altered postnatal stem cell behavior and a failure in postnatal muscle growth. Dev Biol, Vol. 281, No. 2 (May), pp. 171-183, 0012-1606

Norrby, M. \& Tågerud, S. (2010). Mitogen-activated protein kinase-activated protein kinase 2 (MK2) in skeletal muscle atrophy and hypertrophy. J Cell Physiol,Vol. 223, No. 1 (Apr), pp.194-201, 0021-9541

Oldfors, A. (2007). Hereditary myosin myopathies. Neuromuscul Disord, Vol. 17, No. 5 (May), pp. 355-367, 0960-8966

Olguin, H.C. \& Olwin, B.B. (2004). Pax-7 up-regulation inhibits myogenesis and cell cycle progression in satellite cells: a potential mechanism for self-renewal. Dev Biol, Vol. 275, No. 2 (Nov), pp. 375-388, 0012-1606

Paul, P.K., Gupta, S.K., Bhatnagar, S., Panguluri, S.K., Darnay, B.G., Choi, Y. \& Kumar, A. (2010). Targeted ablation of TRAF6 inhibits skeletal muscle wasting in mice. J Cell Biol, Vol. 191, No. 7 (Dec), pp. 1395-1411, 0021-9525

Pedersen, B.K. \& Febbraio, M.A. (2008). Muscle as an endocrine organ: focus on musclederived interleukin-6. Physiol Rev, Vol. 88, No. 4 (Oct), pp. 1379-1406, 0031-9333

Perdiguero, E., Ruiz-Bonilla, V., Serrano, A.L \&, Muñoz-Cánoves,, P. (2007). Genetic deficiency of p38alpha reveals its critical role in myoblast cell cycle exit: the p38alpha-JNK connection. Cell Cycle, Vol. 6, No. 11 (Jun), pp. 1298-1303, 1538-4101

Penna, F., Costamagna, D., Fanzani, A., Bonelli, G., Baccino, F.M. \& Costelli, P. (2010a). Muscle wasting and impaired myogenesis in tumor bearing mice are prevented by ERK inhibition. PLoS One, Vol. 5, No. 10 (Oct), e13604, 1932-6203

Penna. F., Bonetto, A., Muscaritoli, M., Costamagna, D., Minero. V.G., Bonelli, G., Rossi Fanelli, F., Baccino, F.M. \& Costelli, P. (2010b). Muscle atrophy in experimental cancer cachexia: Is the IGF-1 signaling pathway involved? Int J Cancer, Vol. 127, No. 7 (Oct), 1796-1717, 0020-7136

Petersen, A.C., McKenna, M.J., Medved, I., Murphy, K.T., Brown, M.J., Della Gatta, P. \& Cameron- Smith, D. (2011). Infusion with the antioxidant $\mathrm{N}$-acetylcysteine attenuates early adaptive responses to exercise in human skeletal muscle. Acta Physiol (Oxf), doi: 10.1111/j.1748- 1716.2011.02344.x, 1748-1708

Pfeifer, U. (1977). Inhibition by insulin of the physiological autophagic breakdown of cell organelles. Acta Biol Med Ger, Vol. 36, No. 1-2, pp. 1691-1694

Plant, P.J., Bain, J.R., Correa, J.E., Woo, M. \& Batt, J. (2009). Absence of caspase-3 protects against denervation-induced skeletal muscle atrophy. J Appl Physiol, Vol. 107, No. 1 (Jul), pp. 224- 234, 8750-7587

Puri, P.L., Wu, Z., Zhang, P., Wood, L.D., Bhakta, K.S., Han, J., Feramisco, J.R., Karin, M. \& Wang, J.Y. (2000). Induction of terminal differentiation by constitutive activation of 
p38 MAP kinase in human rhabdomyosarcoma cells. Genes Dev, Vol. 14, No. 5 (Mar), pp. 574-584, 0890-9369

Raman, M., Chen, W. \& Cobb, M.H. (2007). Differential regulation and properties of MAPKs. Oncogene,Vol. 26, No. 22 (May), pp. 3100-3112, 0950-9232

Ramamoorthy, S., Donohue, M. \& Buck, M. (2009). Decreased Jun-D and myogenin expression in muscle wasting of human cachexia. Am J Physiol Endocrinol Metab,Vol. 297, No. 2 (Aug), pp. E392-E401, 0193-1849

Romanello, V., Guadagnin, E., Gomes, L., Roder, I., Sandri, C., Petersen, Y., Milan, G., Masiero, E., Del Piccolo, P., Foretz ,M., Scorrano, L., Rudolf, R. \& Sandri M. (2010). Mitochondrial fission and remodelling contributes to muscle atrophy. EMBO J, Vol. 29, No. 10 (May), pp.1774-1785, 0261-4189

Rommel, C., Clarke, B.A., Zimmermann, S., Nunez, L., Rossman, R., Reid, K., Moelling, K., Yancopoulos, G.D. \& Glass, D.J. (1999). Differentiation stage-specific inhibition of the Raf- MEK-ERK pathway by Akt. Science,Vol. 286, No. 5445 (Nov), pp. 1738$1741,0036-8075$

Rommel, C., Bodine, S.C., Clarke, B.A., Rossman, R., Nunez, L., Stitt, T.N., Yancopoulos, G.D. \& Glass, D.J. (2001). Mediation of IGF-1-induced skeletal myotube hypertrophy by $\mathrm{PI}(3) \mathrm{K} / \mathrm{Akt} / \mathrm{mTOR}$ and PI(3)K/Akt/GSK3 pathways. Nat Cell. Biol, Vol. 3, No. 11 (Nov), pp. 1009-1013, 1465-7392

Rosner, M., Hanneder, M., Siegel, N., Valli, A. \& Hengstschläger, M. (2008). The tuberous sclerosis gene products hamartin and tuberin are multifunctional proteins with a wide spectrum of interacting partners. Mutat Res, Vol. 658, No. 3 (Mar-Apr), pp. 234-246, 1383-5742

Ruff, R.L. \& Secrist, D. (1984). Inhibitors of prostaglandin synthesis or cathepsin B prevent muscle wasting due to sepsis in the rat. J Clin Invest, Vol. 73, No. 5 (May), pp. 14831486, 0021-9738

Saido, T.C., Sorimachi, H. \& Suzuki, K. (1994). Calpain: new perspectives in molecular diversity and physiological-pathological involvement. FASEB J, Vol. 8, No. 11 (Aug), pp. 814-822, 0892-6638

Sandri, M. (2002). Apoptotic signaling in skeletal muscle fibers during atrophy. Curr OpinClin Nutr Metab Care, Vol. 5, No. 3, (May), pp. 249-253, 1363-1950

Sandri, M., Sandri, C., Gilbert, A., Skurk, C., Calabria, E., Picard, A., Walsh, K., Schiaffino, S., Lecker, S.H. \& Goldberg, A.L. (2004). Foxo transcription factors induce the atrophyrelated ubiquitin ligase atrogin-1 and cause skeletal muscle atrophy. Cell, Vol.117, No. 3 (Apr), pp.399-412, 0092-8754

Sakamoto. K., Aschenbach. W.G., Hirshman. M.F. \& Goodyear, L.J. (2003). Akt signaling in skeletal muscle: regulation by exercise and passive stretch. Am J Physiol Endocrinol Metab, Vol. 285, No. 5 (Nov), pp. E1081-E1088, 0193-1849

Schakman, O., Kalista, S., Bertrand, L., Lause, P., Verniers, J., Ketelslegers, J.M. \& Thissen, J.P. (2008). Role of Akt/GSK-3beta/beta-catenin transduction pathway in the muscle anti- atrophy action of insulin-like growth factor-I in glucocorticoid-treated rats. Endocrinology,Vol. 149, No. 8 (Aug), pp. 3900-3908, 0013-7227

Schakman, O., Gilson, H., Kalista, S. \& Thissen, J.P. (2009). Mechanisms of muscle atrophy induced by glucocorticoids. Horm Res, Vol. 72, No. 1 Suppl (Nov), pp. 36-41, 03010163 
Schiaffino, S. \& Mammucari, C. (2011). Regulation of skeletal muscle growth by the IGF1Akt/PKB pathway: insights from genetic models. Skelet Muscle, Vol. 1, No. 1 (Jan), 4, 2044-5040

Schmitt, T.L., Martignoni, M.E., Bachmann, J., Fechtner, K., Friess, H., Kinscherf, R. \& Hildebrandt, W. (2007). Activity of the Akt-dependent anabolic and catabolic pathways in muscle and liver samples in cancer-related cachexia. J Mol Med, Vol. 85, No. 6 (Jun), pp. 647-654, 0946- 2716

Schultz, E. \& McCormick, K.M. (1994). Skeletal muscle satellite cells. Rev Physiol Biochem Pharmacol, Vol. 23, pp. 213-257, 0303-4240

Scott, S.V. \& Klionsky, D.J. (1998). Delivery of proteins and organelles to the vacuole from the cytoplasm. Curr Opin Cell Biol, Vol. 10, No. 4 (Aug), pp. 523-529, 0955-0674

Shi, H., Zeng, C., Ricome, A., Hannon, K.M., Grant, A.L. \& Gerrard, D.E. (2007). Extracellular signal-regulated kinase pathway is differentially involved in betaagonist-induced hypertrophy in slow and fast muscles. Am J Physiol Cell Physiol,Vol. 292, No. 5 (May), pp. C1681-C1689, 0363-6143

Shi, H., Scheffler, J.M., Pleitner, J.M., Zeng, C., Park, S., Hannon, K.M., Grant, A.L. \& Gerrard, D.E. (2008). Modulation of skeletal muscle fiber type by mitogen-activated protein kinase signaling. FASEB J, Vol. 22, No. 8 (Aug), pp. 2990-3000, 0892-6638

Shi, H., Scheffler, J.M., Zeng, C., Pleitner, J.M., Hannon, K.M., Grant, A.L. \& Gerrard, D.E. (2009). Mitogen-activated protein kinase signaling is necessary for the maintenance of skeletal muscle mass. Am J Physiol Cell Physiol, Vol. 296, No. 5 (May), pp. C1040C1048, 0363-6143

Sinha-Hikim, I., Braga, M., Shen, R. \& Sinha Hikim, A.P. (2007). Involvement of c-Jun NH2terminal kinase and nitric oxide-mediated mitochondria-dependent intrinsic pathway signaling in cardiotoxin-induced muscle cell death: role of testosterone. Apoptosis, Vol. 12, No. 11 (Nov), pp. 1965-1978, 1360-8185

Smuder, A.J., Kavazis, A.N., Hudson, M.B., Nelson, W.B. \& Powers, S.K. (2010). Oxidation enhances myofibrillar protein degradation via calpain and caspase-3. Free Radic Biol Med, Vol. 49, No. 7 (Oct), pp. 1152-1160, 0891-5849

Stitt, T.N., Drujan, D., Clarke, B.A., Panaro, F., Timofeyva, Y., Kline, W.O., Gonzalez, M., Yancopoulos, G.D. \& Glass, D.J. (2004). The IGF-1/PI3K/Akt pathway prevents expression of muscle atrophy-induced ubiquitin ligases by inhibiting FOXO transcription factors. Mol Cell, Vol.14, No. 3 (May), pp. 395-403, 1097-2765

Stokoe, D., Engel, K., Campbell, D.G., Cohen, P. \& Gaestel, M. (1992). Identification of MAPKAP kinase 2 as a major enzyme responsible for the phosphorylation of the small mammalian heat shock proteins. FEBS Lett, Vol. 313, No. 3 (Nov), pp. 307313, 0014-5793

Sugiura, T., Abe, N., Nagano, M., Goto, K., Sakuma, K., Naito, H., Yoshioka, T. \& Powers, S.K. (2005). Changes in PKB/Akt and calcineurin signaling during recovery in atrophied soleus muscle induced by unloading. Am J Physiol Regul Integr Comp Physiol, Vol. 288, No. 5 (May), pp. R1273-R1278, 0363-6119

Supinski, G.S., Ji, X. \& Callahan, L.A. (2009). The JNK MAP kinase pathway contributes to the development of endotoxin-induced diaphragm caspase activation. Am J Physiol Regul Integr Comp Physiol, Vol. 297, No. 3 (Sep), pp. R825-R834, 0363-6119.

Suzuki, K., Hata, S., Kawabata, Y. \& Sorimachi, H. (2004). Structure, activation, and biology of calpain. Diabetes, Vol. 53, No. 1 Suppl (Feb), pp. S12-S8, 0012-1797 
Temparis, S., Asensi, M., Taillandier, D., Aurousseau, E., Larbaud, D., Obled, A., Béchet, D., Ferrara, M., Estrela, J.M. \& Attaix, D. (1994). Increased ATP-ubiquitin dependent proteolysis in skeletal muscles of tumor-bearing rats. Cancer Res, Vol. 54, No. 21 (Nov), pp. 5568-5573, 0008-5472

Tessitore, L., Costelli, P., Bonetti, G. \& Baccino, F.M. (1993). Cancer cachexia, malnutrition, and tissue protein turnover in experimental animals. Arch Biochem Biophys, Vol 306, No. 1 (Oct), pp. 52-58, 0003-9861

Tessitore, L., Costelli, P. \& Baccino, F.M. (1994). Pharmacological interference with tissue protein hypercatabolism in tumor-bearing rats. Biochem J, Vol. 299, No. Pt 1 (Apr), pp. 71-78, 0264- 6021.

Tidball, J.G. \& Spencer, M.J. (2002). Expression of a calpastatin transgene slows muscle wasting and obviates changes in myosin isoform expression during murine muscle disuse. J Physiol, Vol. 545, No. Pt 3 (Dec), pp. 819-828, 0022-3751

Tintignac, L.A., Lagirand, J., Batonnet, S., Sirri,V., Leibovitch, M.P. \& Leibovitch, S.A. (2005). Degradation of MyoD mediated by the SCF (MAFbx) ubiquitin ligase. J Biol Chem, Vol. 280, No. 4 (Jan), pp. 2847-2856, 0021-9258

Tisdale, M.J. (2008). Catabolic mediators of cancer cachexia. Curr Opin Support Palliat Care, Vol.2, No. 4 (Dec), pp. 256-261, 1751-4258

Van der Velden, J.L., Langen, R.C., Kelders, M.C., Wouters, E.F., Janssen-Heininger, Y. M. \& Schols, A.M. (2006). Inhibition of glycogen synthase kinase-3beta activity is sufficient to stimulate myogenic differentiation. Am. J. Physiol. Cell. Physiol, Vol. 290, No. 2 (Feb), pp. C453-C462, 0363-6143

Verzola, D., Procopio, V., Sofia, A., Villaggio, B., Tarroni, A., Bonanni, A., Mannucci, I., De Cian, F., Gianetta, E., Saffioti, S. \& Garibotto, G. (2011). Apoptosis and myostatin mRNA are upregulated in the skeletal muscle of patients with chronic kidney disease. Kidney Int, Vol. 79, No. 7 (Apr), pp. 773-782, 0085-2538

Wang, X., Hu, Z., Hu, J., Du, J. \& Mitch, W.E. (2006). Insulin resistance accelerates muscle protein degradation: Activation of the ubiquitin-proteasome pathway by defects in muscle cell signaling. Endocrinology, Vol. 147, No. 9 (Sep), pp. 4160-4168, 0013-7227

Wang, X.H., Zhang, L., Mitch, W.E., LeDoux, J.M., Hu, J. \& Du, J. (2010). Caspase-3 cleaves specific $19 \mathrm{~S}$ proteasome subunits in skeletal muscle stimulating proteasome activity. J Biol Chem, Vol. 285, No. 28 (Jul), pp. 21249-21257, 0021-9258

Waterlow, J.C. (1984). Protein turnover with special reference to man. Q J Exp Physiol, Vol. 69, No. 3 (Jul), pp. 409-438, 0958-0670

White, J.P., Baynes, J.W., Welle, S.L., Kostek, M.C., Matesic, L.E., Sato, S. \& Carson, J.A. (2011). The Regulation of Skeletal Muscle Protein Turnover during the Progression of Cancer Cachexia in the Apc Mouse. PLoS One, Vol. 6, No. 9, e24650, 1932-6203

Williams, A.B., Decourten-Myers, G.M., Fischer, J.E., Luo, G., Sun, X. \& Hasselgren, P.O. (1999). Sepsis stimulates release of myofilaments in skeletal muscle by a calciumdependent mechanism. FASEB J, Vol. 13, No. 11 (Aug), pp. 1435-1443, 0892-6638

Wray, C.J., Sun, X., Gang, G.I. \& Hasselgren, P.O. (2002). Dantrolene downregulates the gene expression and activity of the ubiquitin-proteasome proteolytic pathway in septic skeletal muscle. J Surg Res, Vol. 104, No. 2 (May), pp. 82-87, 0022-4804

Wu, R., Kausar, H., Johnson, P., Montoya-Durango, D.E., Merchant, M. \& Rane, M.J. (2007). Hsp27 regulates Akt activation and polymorphonuclear leukocyte apoptosis by 
scaffolding MK2 to Akt signal complex. J Biol Chem, Vol. 282, No. 30 (Jul), pp. 21598-21608, 0021-9258

Yang, W., Chen, Y., Zhang, Y., Wang, X., Yang, N. \& Zhu, D. (2006). Extracellular signalregulated kinase 1/2 mitogen-activated protein kinase pathway is involved in myostatin-regulated differentiation repression. Cancer Res, Vol. 66, No. 3 (Feb), pp. 1320-1326, 0008-5472

Yang, S.Y., Hoy, M., Fuller, B., Sales, K.M., Seifalian, A.M. \& Winslet, M.C. (2010). Pretreatment with insulin-like growth factor I protects skeletal muscle cells against oxidative damage via PI3K/Akt and ERK1/2 MAPK pathways. Lab Invest, Vol. 90, No. 3 (Mar), pp. 391-401, 0023-6837

Zhang, L., Wang, X.H., Wang, H., Du, J. \& Mitch, W.E (2010). Satellite cell dysfunction and impaired IGF-1 signaling cause CKD-induced muscle atrophy. J Am Soc Nephrol, Vol. 21, No. 3 (Mar), pp. 419-427, 1046-6673

Zhao, J., Brault, J.J., Schild, A., Cao, P., Sandri, M., Schiaffino, S., Lecker, S.H. \& Goldberg, A.L. (2007). FoxO3 coordinately activates protein degradation by the autophagic/lysosomal and proteasomal pathways in atrophying muscle cells. Cell Metab,Vol. 6, No. 6 (Dec), pp. 472-483, 1550-4131 


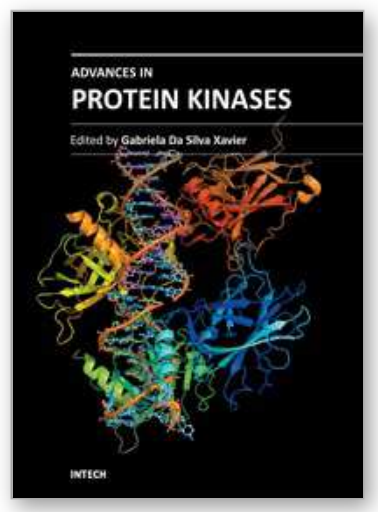

\author{
Advances in Protein Kinases \\ Edited by Dr. Gabriela Da Silva Xavier
}

ISBN 978-953-51-0633-3

Hard cover, 374 pages

Publisher InTech

Published online 05, June, 2012

Published in print edition June, 2012

Proteins are the work horses of the cell. As regulators of protein function, protein kinases are involved in the control of cellular functions via intricate signalling pathways, allowing for fine tuning of physiological functions. This book is a collaborative effort, with contribution from experts in their respective fields, reflecting the spirit of collaboration - across disciplines and borders - that exists in modern science. Here, we review the existing literature and, on occasions, provide novel data on the function of protein kinases in various systems. We also discuss the implications of these findings in the context of disease, treatment, and drug development.

\title{
How to reference
}

In order to correctly reference this scholarly work, feel free to copy and paste the following:

Fabio Penna, Domiziana Costamagna, Andrea Camperi, Maurizio Muscaritoli, Francesco M. Baccino and Paola Costelli (2012). Protein Kinases in the Pathogenesis of Muscle Wasting, Advances in Protein Kinases, Dr. Gabriela Da Silva Xavier (Ed.), ISBN: 978-953-51-0633-3, InTech, Available from:

http://www.intechopen.com/books/advances-in-protein-kinases/protein-kinases-in-the-pathogenesis-of-musclewasting

\section{INTECH}

open science | open minds

\section{InTech Europe}

University Campus STeP Ri Slavka Krautzeka 83/A 51000 Rijeka, Croatia Phone: +385 (51) 770447

Fax: +385 (51) 686166 www.intechopen.com

\section{InTech China}

Unit 405, Office Block, Hotel Equatorial Shanghai No.65, Yan An Road (West), Shanghai, 200040, China 中国上海市延安西路65号上海国际贵都大饭店办公楼 405 单元 Phone: +86-21-62489820

Fax: $+86-21-62489821$ 
(C) 2012 The Author(s). Licensee IntechOpen. This is an open access article distributed under the terms of the Creative Commons Attribution 3.0 License, which permits unrestricted use, distribution, and reproduction in any medium, provided the original work is properly cited. 